\title{
Local and overall wind pressure and force coefficients for solar panels
}

\author{
Ted Stathopoulos ${ }^{1}$, Ioannis Zisis ${ }^{2}$, Eleni Xypnitou ${ }^{1}$ \\ ${ }^{1}$ Department of Building, Civil and Environmental Engineering, Concordia University, Montreal, Quebec, Canada \\ ${ }^{2}$ Department of Civil and Environmental Engineering, Florida International University, Miami, FL, USA
}

\begin{abstract}
This paper reports on an experimental study carried out to better understand the wind pressure distribution on stand-alone panel surfaces and panels attached to flat building roofs. A complex model capable to incorporate solar panels at different locations and various inclinations was constructed at a 1:200 geometric scale. Three model panels equipped with pressure taps on both surfaces (36 in total) for point and area-averaged pressure measurements were used. Pressure and force coefficients were computed for every pressure tap and for all the panels. Different configurations were tested under similar conditions in order to examine the effect of various parameters on the experimental results. A minimal gap occurred between the solar panels and the roof of the model. The study found that the net values of pressure coefficients corresponding to different configurations are affected by the panel inclination for the critical 135-degree wind direction, for which panels on the back location undergo higher suctions in comparison to those in the front. The effect of building height on the solar collector total load is minimal, whereas corner panels are subjected to higher net loads for critical azimuths. Simplified net pressure coefficients for the design of solar panels are provided.
\end{abstract}


Keywords: Codes and standards, force coefficient, ground level, low-rise building, photovoltaic panel, pressure coefficient, rooftop, design, solar collector, wind tunnel

\section{Highlights:}

- Comprehensive boundary-layer wind tunnel study to evaluate wind pressures on solar collectors on roofs and on ground

- Wind-induced pressure coefficients for solar panels are provided

- Suggestions for wind code and standard provisions are made 


\section{Introduction}

The evaluation of wind-induced loads applied on solar panels plays a very important role for design purposes. During the last decades, a strong interest has been developed towards renewable energy resources and to this end the utilisation of solar panels has been expanded. However, the effect of a number of factors such as the upstream exposure, the landscape, the panel inclination and location, the building height for panels attached to building roofs and the like have to be carefully considered in all experimental and computational procedures. Experiments can be performed nowadays with more sophisticated and cutting edge technology resulting in more accurate results.

The main scope of this research project is the systematic study of wind-induced pressures applied on the surface of solar panels, placed on the ground or on the roof of buildings. This project followed a detailed literature review, which compared experimental results generated by previous studies (Stathopoulos et al. 2012). Although several ad hoc studies of wind loads on particular solar system configurations have been commissioned and completed, this exercise included only studies reported in the open literature. The review demonstrated clearly the discrepancy among the results of previous studies, even those carried out under nominally similar conditions, which in turn explains the lack of design provisions for solar collectors and PV systems in wind loading standards and codes of practice at present. The literature review concluded that a new comprehensive study would be necessary in order to put together a set of provisions for different configurations including both point and area-averaged loads.

The current study performed in the atmospheric boundary layer wind tunnel of Concordia University, examines the influence of a number of factors such as building height, panel 
inclination, and location, as well as, the wind direction, which has a direct impact on design decisions for these structures. The collection of the experimental data for a number of different configurations, in addition to their analysis and transformation to pressure, force, and areaaveraged pressure coefficients was of major significance in this work.

\section{Previous studies}

Several studies, that include both small and large scale experiments as well as numerical simulation approaches, examined the wind-induced load on solar panels. The results from these studies, some of which correspond to similar configurations, show significant differences. In an effort to categorize the available literature, the findings were organized separately for solar collectors on flat or pitched roofs and stand-alone panels - see Fig. 1. Also, the inclination of the collector, as well as its location on the roof, has been taken into account. A summary of the studies considered is presented in Table 1 (solar panels attached on flat roofs) and Table 2 (solar panels attached near roof corners and edges). A detailed critical discussion can be found in Xypnitou (2012). In addition to the experimental study of wind-induced pressures on solar panels, recently published studies are focusing on identifying important parameters for both experimentation and data analysis in wind tunnel testing (Kopp and Banks 2013), as well as, details related to the use of experimental data in the structural design of such systems (Maffei et al. 2013).

A representative comparison of peak net force coefficients obtained from two different studies (Erwin et al. 2011 and Saha et al. 2011) on solar panels inclined at 15 degrees is presented in Fig. 2. The absolute minimum and maximum net force coefficients in both studies compare well only for 0-degree azimuth. It should also be noted that for certain wind directions 
the force coefficient values follow a similar pattern (e.g. 0 - 75 degrees for minimum net force coefficients) whereas significant differences are noticed for other wind directions. While this can be partially attributed to the different geometries considered for the building and solar panel models, the need for additional experimental efforts on the subject is apparent.

\section{Experimental Study Description}

The main scope of this study was a systematic examination of wind-induced pressures applied on the surface of solar panels, placed on the ground or on the roof of buildings. The size and the configurations of solar panel systems vary greatly, with some typical solar panel systems presented in Fig. 3a (mounted on the ground) and Fig. 3b (mounted on roofs). For the present study the solar panel model was selected to have a relatively larger size which served a dual purpose. First, it allowed the accommodation of the tubing system for the pressure taps on both the top and bottom surfaces of the panels. The second objective was related to wind load criteria that should ultimately provide adequate information for design of the racking systems that panels are mounted on. These racking systems accommodate arrays of panels rather than individual modules (see Figs. 3a and 3b) and are generally much larger in terms of width and length compared to single solar panels.

The experiments for this study were carried out in the Building Aerodynamics Laboratory of Concordia University. Considering the simulated flow properties for the specific wind tunnel as well as the scope of the study, a geometric scale of 1:200 was selected and the tests were performed for the most critical open terrain exposure. The model consists of a specially-designed rectangular flat-roof building on top of which three identical panels were attached - see Fig. 4. The external dimensions of the building model are $15.3 \mathrm{~cm}$ (length) $\times 9.8 \mathrm{~cm}$ (width) and the 
height corresponding to the two different cases that were examined is $3.5 \mathrm{~cm}$ and $8 \mathrm{~cm}$ respectively. The dimensions of the three panels are $4.3 \mathrm{~cm}$ (length) x $2.8 \mathrm{~cm}$ (width) x $1 \mathrm{~mm}$ (thickness). Fig. 5 shows the three panels in the so-called front location, along with the position of all 36 pressure taps attached to the panels measuring the pressure on its upper and lower surface. On-line algebraic difference of their values provides the instantaneous pressure load. The number of taps used on each panel was restricted by physical limitations with regards to the tubing space requirements and the desire to avoid any extraneous flow disturbance; while at the same time keeping the scaling requirements.

The panels were located on two different locations of the roof, the one closer to the side facing the 0-degree wind direction (front location - see Fig. 6a) and the other closer to the opposite side (back location - see Fig. 6b). For the front location, the distance between the panel base and the front edge is $2.2 \mathrm{~cm}$ and $1.2 \mathrm{~cm}$ from the side edge. For the back location, the base of the panel is placed at a distance of $5.2 \mathrm{~cm}$ from the front edge of the building and $1.2 \mathrm{~cm}$ from the side edge. The model allows the inclination of the panels to range from 20 to 45 degrees. The inclination mechanism leaves a small gap underneath, which represents the gap that actual panels form from the roof surface. In typical solar panel arrays, this gap is highly variable depending on the type of racking system used as well as local topography, regulations, climate etc. Previous studies have shown that the size of this gap is not as important as its existence. The objective of the model configuration was to account for this clearance and consider its effect on the windinduced loads.

The building model with the panels attached is symmetrical and for this reason the tested wind directions ranged from 0 to 180 degrees while a total number of 13 wind attack angles were tested with 15 -degree intervals. 
In order to measure the wind loads applied on the solar panels, 36 pressure taps in total were attached on the panels measuring the pressure on the upper and lower surface of the panel. Each panel was equipped with 12 pressure taps, 6 on each side connected with tubing that passed inside the building through the roof. The brass taps were connected to transducers through flexible urethane tubes. A brass restrictor was placed at the 10/24 of the total length of the tubing so as the effects of the frequency response to be virtually eliminated. The sampling frequency was set at $312.5 \mathrm{~Hz}$ and a total of 8200 frames were collected. The scan duration was approximately 26.2 seconds, corresponding to a full-scale storm of approximately 1 hour.

Considering the three panels as one, the pressure taps were located at equal distances among them. It should be mentioned that in order to accommodate the tubing through the collectors and avoid interfering with the wind flow, this was the maximum number of pressure taps we could have used. Using a larger scale, say 1:20 or 1:50, would be indeed beneficial for Re effects and for the inclusion of additional pressure taps, except that it would destroy the proper simulation of the natural wind characteristics, particularly the critical value of turbulence intensity at the building / panel height (Tieleman et al. 1978, 1997 and 1998). In fact violating the geometric scale may be one reason for the extensive discrepancies found among the results of previous studies (Stathopoulos et al. 2012). Given that the codification process followed in this study does not suggest different provisions for edge and corner specific areas, it is expected that the overall values are representative of the wind-induced pressures on the great majority of panels used in practice.

The pressure measurement results were normalized in order to obtain dimensionless coefficients and compare them to either different testing configurations or other studies. The mean and peak pressure coefficients have been derived by using the following definitions: 
$C_{p, \text { mean }}=\frac{p_{\text {mean }}-p_{a}}{1 / 2 \rho U^{2}}$

$C_{p, p e a k}=\frac{p_{\text {peak }}-p_{a}}{1 / 2 \rho U^{2}}$

where $\rho$ is the air density $\left(\mathrm{kg} / \mathrm{m}^{3}\right)$; $\mathrm{U}$ is the mean wind speed at solar panel mid-height $(\mathrm{m} / \mathrm{s}) ; \mathrm{p}_{\mathrm{a}}$ is the ambient atmospheric pressure $(\mathrm{Pa})$; $\mathrm{p}_{\text {mean }}$ is the mean surface pressure $(\mathrm{Pa})$ and $\mathrm{p}_{\text {peak }}$ is the peak surface pressure $(\mathrm{Pa})$. The peak pressure coefficients were estimated using the method proposed by Wang and Stathopoulos (2006). The force coefficients for each panel, considering that the area corresponding to each pressure tap was approximately equal, were calculated by adding the net local pressure coefficients and then dividing by the number of the pressure taps. While area-averaged pressure coefficients correspond to any area of the panel (e.g. half, quarter etc), force coefficients refer to one or a row of solar panels. Finally, the net pressure and force coefficients were obtained by considering the simultaneous effect of both top and bottom pressure taps.

The experiments were performed for two different building heights, representing an equivalent full-scale height of $7 \mathrm{~m}$ and $16 \mathrm{~m}$; and two different panel locations (i.e. front and back located panels). Moreover, a third configuration was examined, for panels located at ground level.

\section{Results and Discussion}

Pressure coefficients, force (or area-averaged pressure) coefficients and comparisons of local and force coefficient values are presented while the effect of panel inclination, building height, panel location and wind direction is discussed for each configuration. It should be noted that after considering the results from all 13 tested wind angles of attack, it was found that the 135- 
degree wind direction is the most critical (Xypnitou 2012); this will be also demonstrated here but, in general, results for the critical 135-degree azimuth have been presented in this paper.

\subsection{Pressure coefficients}

\subsubsection{Effect of panel inclination}

In order to investigate the effect of panel inclination, a thorough study of measured pressure coefficients for several configurations is necessary. Only the extreme values for both building heights (i.e. $7 \mathrm{~m}$ and $16 \mathrm{~m}$ ) and both panel locations (i.e. front and back) have been considered and presented here.

For the upper surface (see Fig. 7a), the maximum $\mathrm{Cp}$ values, regardless of the point on the panel where they appear, follow the same pattern for all panel inclinations while minimum values vary with different inclination. The pressure coefficients corresponding to the trends for 7 $\mathrm{m}$ and $16 \mathrm{~m}$ front location decrease with increasing inclination while those corresponding to the back location increase with increasing inclination. For the stand-alone-panels, increase of the panel inclination leads to greater suction and consequently the peak appears for 45 -degree panel inclination which is overall the greatest suction.

The minimum and the maximum values of pressure coefficients, on the lower surface of the panel (see Fig. 7b), differ only slightly for different building heights and panel locations. However, the greatest suction occurs for panels on the $16 \mathrm{~m}$ high building, back located and inclined by 20 degrees, while the positive greatest value of the pressure coefficient for the $7 \mathrm{~m}$ high building, at the back location and 20-degree panel inclination.

The net values of the peak pressure coefficients referring to the entire solar panel - regardless of the point on the panel where they appear - are presented in Fig. 8. The maximum $\mathrm{Cp}$ values 
decrease somewhat with increasing panel inclination (from -0.5 to -1.3 ). On the contrary, the minimum values show smaller suction with increasing panel inclination for both $7 \mathrm{~m}$ and $16 \mathrm{~m}$ building height and front location. The trends for back location show that increasing inclination results in higher suction for every building height and the stand-alone case as well. The different behaviour for front and back panels comes from the fact that different panel locations affect differently the wind flow. The front-located panels are dominated by the flow separation at the building roof corner whereas the back located panels are experiencing more complex flow due to the combined building- and front panel-induced separation. The panel inclination also contributes to this phenomenon and a different pressure field is created for different panel inclinations.

\subsubsection{Effect of building height}

Different model configurations were tested in order to evaluate the effect of building height on the wind-induced load on solar panels. Figs. 9 and 10 show how the local peak pressure coefficients, from all pressure taps corresponding to different panel inclinations, vary with building height for the most critical case of 135-degree wind direction.

The peak pressure coefficients for front located panels are depicted in Fig. 9 for the upper, lower panel surface and the net values. Fig. 9a shows that increasing building height results in lower suction for every panel inclination. On the contrary, the suction is smaller for the case of stand-alone panels and for 20-degree panel inclination. As far as the lower surface of the panel is concerned, the minima and maxima of pressure coefficients for front location and 135-degree wind direction follow the same pattern, as shown in Fig. 9b. Overall, slightly greater suctions do occur when the building height increases. Fig. 9c depicts the net values of peak pressure 
coefficients as a function of building height. Maximum values range from -1.2 to +0.2 as a function of the building height. As far as the minima are concerned, the $16 \mathrm{~m}$ high building results in lower suctions for every panel inclination compared to those appearing for $7 \mathrm{~m}$ high building. For panels at the ground level, suction takes its greatest value for 40 - and 45 -degree panel inclination, while the lowest suction appears for 20-degree panel inclination. The trend of 30-degree panel inclination ranges from -4.2 to -3.7 and thus no significant building height effect is observed.

For the back location, the trends remain almost constant for both building heights and standalone panels. Peak pressure coefficients at the lower surface for back location and 135-degree wind direction (see Fig. 10b) show that increasing building height results in higher suction in total. Maximum values are almost constant and remain within the same range. Finally, the net values of pressure coefficients for the critical 135-degree wind direction and back location (see Fig. 10c) show that there are differences compared to Fig. 9c indicating that panel location plays an important role especially as far as the minimum pressure coefficients are concerned. The trends for the minimum values of 30-, 40- and 45-degree panel inclination range from -4.6 to 3.7 while that of 20-degree panel inclination takes values from -2.9 to -2.1 . Further comparison between the two figures also makes evident the fact that the magnitudes of minimum pressure coefficients are greater for the back location and their range is within -5 and -4 for $30-, 40-, 45-$ degree panel inclination.

\subsubsection{Effect of panel location and wind direction}

This section presents the effect of wind direction and panel location on experimental results expressed as net peak pressure coefficients. Figs. 11 and 12 demonstrate how the net peak 
pressure coefficients vary as a function of wind direction for stand-alone panels and panels attached to $7 \mathrm{~m}$ and $16 \mathrm{~m}$ high building when panels are inclined by 20,30, 40 and 45 degrees.

More specifically, Fig. 11 shows the peak pressure coefficients for the case of stand-alone panels for variable panel inclination. The maximum and minimum peaks appear for 30- and 135degree wind direction respectively. It is also evident that suction is greater than overpressure (i.e. positive pressure) in absolute value. The cases where the panels are attached to the roof of the 7 $\mathrm{m}$ high building, located at the front or the back of the roof, are shown in Fig. 12a. For wind directions 120 and 135 degrees the extreme values do occur for 45- and 30-degree panel inclination respectively, when the panel is located on the back of the roof. The maximum positive pressure can be observed for 30-degree wind direction when the panels are located on the front position and are inclined by 45 degrees. Fig. $12 \mathrm{~b}$ presents the case where the panels are attached to a $16 \mathrm{~m}$ high building. Clearly, suction is overall greater than overpressure in terms of absolute values. In addition, greater suction appears for back located panels while overpressure is greater for front located panels. These phenomena can be attributed to the flow separation occurring due to the sharp building edges resulting in high negative pressure field at the rear panel location. The greatest suction occurs for 135-degree wind direction when the panel location is back, and the panel inclination is 30 degrees, since airflow moves towards the building at an oblique wind angle of attack and, therefore two delta wing vortices are developed across its edges. The extreme values for overpressure appear for 45-degree wind direction, 40degree panel inclination and front location. 


\subsection{Force coefficients}

\subsubsection{Effect of panel inclination}

This section refers to the effect of panel inclination on force coefficients for panels attached to buildings of different heights and stand-alone panels. The peak values of force coefficients are presented for each panel as a function of panel inclination.

Fig. 13 demonstrates the net peak values of force coefficients for the case of stand-alone panels and for 135-degree wind direction. The trends of force coefficients for the three panels follow the same pattern for both minima and maxima. The suction observed becomes greater with increasing panel inclination, while greater overpressure occurs for smaller panel inclination. Panel 1 shows the greatest suction for 45-degree panel inclination followed by panel 2 and 3 for panel identification, please see Fig. 5 .

Fig. 14 shows the minimum values of force coefficients for panels mounted on $7 \mathrm{~m}$ and $16 \mathrm{~m}$ high buildings - (a) and (b) respectively. The trends for both building heights follow the same pattern for the front located panels, which does not differ significantly from those corresponding to back-located panels. As it can be observed, the greatest suction occurs for panel 1 attached to $7 \mathrm{~m}$ high building, located at the back, when inclined by 45 degrees, which is followed by panel 1 located at the front. For panel 1 attached to $16 \mathrm{~m}$ high building, the greatest suction occurs when it is back located and inclined by 30 degrees. For panels 2 and 3 front located, the suction is greater compared to that corresponding to back location for both building heights in terms of absolute values. Panel 2 suffers smaller suction than panel 1, while panel 3 experiences the smallest suction that becomes even smaller for back location in terms of absolute values. In all cases, the results are consistent with the anticipated interaction of the conical vortices of the 
separated flow along the roof edges with the inclined panel surfaces contributing to generating additional vorticity and higher suctions.

Figs. $15 \mathrm{a}$ and $15 \mathrm{~b}$ depict the maximum values of force coefficients as a function of panel inclination for building heights of $7 \mathrm{~m}$ and $16 \mathrm{~m}$ respectively. These values for all three panels range from 0 to approximately -1 for both front and back location. The greatest value of maximum force coefficients appears for panel 3 when attached to a $16 \mathrm{~m}$ high building, front located and inclined by 20 degrees. Slight overpressure is observed for panel 3, at 20-degree panel inclination, front location and $16 \mathrm{~m}$ high building.

\subsubsection{Effect of building height}

The effect of building height on force coefficients is examined in this section for the three panels considered. The net minimum and maximum force coefficient values as a function of building height are depicted in Fig. 16 for panels located at the front position. As far as the minima are concerned - see Fig. 16a - the 20- and 30-degree panel 1 inclination trend shows that increasing building height results in lower suction, while the opposite happens for 40- and 45degree panel inclination. The trends of 40- and 45-degree panel 2 inclinations remain almost constant with building height. However, the trends of 20- and 30-degree panel 2 inclinations show greater suction with increasing building height. Panel 3 experiences significantly smaller suction for both building heights. Stand-alone panels inclined by 20 degrees show the smallest suction, which becomes greater for the maximum building height. Fig. 16b depicts the net maximum values of force coefficients as a function of building height. It is clearly demonstrated that increasing building height results in increased values of force coefficients, which remain negative. Positive force coefficients appear only for panel 3, inclined by 20 degrees. For the 
interval $7 \mathrm{~m}$ to $16 \mathrm{~m}$ building height, the values of force coefficients range from -1 to 0 for all cases, while suction is greater for stand-alone panels.

The net peak values of force coefficients are depicted in Fig. 17 for the back location. The net minimum values in Fig. 17a show that higher suction appears for 30-, 40-, 45-degree panel 1 inclination. The greatest suction occurs for 30-degree panel inclination. For 45-degree panel inclination increasing building height results in lower suction while for 20-, 30- and 40-degree in higher suction. As far as panels 2 and 3 are concerned, increasing building height results in smaller suction for 20-, 40-, 45-degree panel inclination, while the opposite happens for 30degree panel inclination. The net maximum values of force coefficients are depicted in Fig. 17b from which can be concluded that, in general, values of force coefficients remain constant. The greatest suction appears for stand-alone panels 1, 2 when inclined by 30 degrees. The net

maximum values of force coefficients range from just below -1 to 0 and remain independent of building height.

Comparison between Fig. 16a and 17a draws to the conclusion that panel location is a parameter affecting the wind flow around the panels significantly and as a result, the force applied on them also depends on this flow. Concluding, the peak net force coefficients, as far as the pressure trends are concerned, are not affected considerably by the building height. Panel 1 is experiencing the greatest suction compared to panel 2 that follows and panel 3 that is subjected to the least suction for both building heights and panel locations.

\subsubsection{Effect of wind direction}

The wind direction effect on force coefficients was examined for the three panels and is presented in this section. The net peak force coefficients are given for panels inclined by 20,30 , 
40 and 45 degrees, for the case of stand-alone panels and those mounted on the $7 \mathrm{~m}$ and $16 \mathrm{~m}$ high building.

Fig. 18a shows the minimum and maximum values of force coefficients for panel 1 as a function of wind direction. It is evident that the 135-degree wind direction is critical since for 45degree panel inclination, the suction takes its greatest value. The maximum value is observed for 30-degree wind direction and 45-degree panel inclination. Figures $18 \mathrm{~b}$ and $18 \mathrm{c}$ refer to peak force coefficients on panels 2 and 3 respectively. In these two figures, the trends follow the same patterns with the only difference being that panel 3 experiences slightly smaller suction and overpressure. For both panels the minimum peak values are observed for 180-degree wind direction and 45-degree panel inclination. The maximum peak values for panel 3 occurs for 0degree wind direction and 40-degree panel inclination, while for panel 2 appears for 30-degree wind direction and 45-degree panel inclination.

Fig. 19 presents the net peak force coefficients for panels 1, 2, 3 when attached to the $7 \mathrm{~m}$ high building for both front and back location. The trends follow similar patterns for the three panels. Differences can be detected regarding the magnitude of their extreme values and the wind direction for which these extremes occur. The minimum peak force coefficients, which are observed for panels 1 and 2, occur for 135-degree wind direction, 30-degree panel inclination, for panels located back and front respectively. Additionally, panel 3 peak force coefficients appear for 180-degree wind direction, 40-degree panel inclination and back location. The maximum peak force coefficient calculated for panel 1 occurs for 30-degree wind direction, 45degree panel inclination, and front location. Panels 2 and 3 show their maximum peak force coefficients for 0-degree wind direction, 45-degree panel inclination and front location. 
The net peak force coefficients for panels attached to the $16 \mathrm{~m}$ high building are depicted in Fig. 20. Similar trends for panels attached to $7 \mathrm{~m}$ and $16 \mathrm{~m}$ high buildings can be observed for all three panels. Panel 1 experiences the greatest suction, followed by panel 2 for which suction is smaller and finally the smallest suction occurs for panel 3. Overpressure is almost the same for panels 1 and 2 and becomes smaller for panel 3. More specifically, for panels 1 and 2 greatest suction occurs for 135-degree wind direction, when panel 1 is back located and inclined by 30degree, and while panel 2 is front located and inclined by 20-degree. Panel 3 gets its extreme minimum value for 120-degree wind direction, when located at the front and inclined by 30 degree. Concerning the maximum values of force coefficients for panels 1 and 2 , the peaks occur for 45-degree wind direction, 40-degree panel inclination and front location. For panel 3 the greatest of the maximum values is observed for 30-degree wind direction, 30-degree panel inclination and front location. Again, these are experimental findings coherent with the windstructure interaction hypotheses based on Building Aerodynamics but quantifiable only through measurements such as those of the present study.

\subsection{Comparison between local pressure coefficients and force coefficients}

This section refers to the net local pressure coefficients measured on every single set of pressure taps (i.e. top/bottom) of panel 1 in comparison with the force coefficients, which are applied, on the whole surface when the panel is located at the front position of the $7 \mathrm{~m}$ high building. Fig. 21 shows the local pressure coefficients for pressure taps 1, 3, 5, 7, 9, 11, and the force coefficients for panel 1 at 20-, 30-, 40- and 45-degree panel inclination - see Fig. 5. The trends corresponding to the examined pressure taps and panel 1 follow the same pattern with respect to the wind direction. The force coefficient values result from the mean value of the local 
pressure coefficients, which are measured separately for every single pressure tap. The most critical values can be detected for wind directions ranging from 120 to 180 degrees. Pressure tap number 1 is experiencing the greatest suction compared to the other taps and even greater than that experienced by the whole panel for all panel inclinations. This is not surprising considering the corner location of pressure tap 1 and the oblique wind directions.

Fig. 21a shows that for a 20-degree inclined panel, the minimum pressure coefficient value appears for 135-degree wind direction at pressure tap number 5 while for panel 1 the minimum force coefficient takes its minimum at 150 -degree. Figures $21 \mathrm{~b}$ and $21 \mathrm{c}$ indicate that pressure and force coefficients become most critical for 135-degree wind direction at pressure tap number 1 and panel 1 for panels inclined by 30 and 40 degrees respectively. For panel inclined by 45 degrees the results are shown in Fig. 21d in which pressure and force coefficients become critical for 120-degree wind direction at pressure tap number 1 and panel 1.

\subsection{Area-averaged pressure coefficients}

The variation of area-averaged pressure coefficients was examined for the critical wind direction of 135 degrees. The area-averaging effect has been assessed by averaging the pressures experienced at increasing numbers of adjacent pressure tabs and assigning them to their corresponding tributary area. The values of peak area-averaged pressure coefficients are examined separately for three different cases, namely: for panels located at the ground level and for panels attached to roofs of two different building heights. The trends follow a similar pattern for the three cases for both minima and maxima. As expected, an increase of the considered area leads to a reduction of the area-averaged pressure coefficient.

Fig. 22a presents the net peak area-averaged pressure coefficients for the case of stand-alone panels. The minimum area-averaged pressure coefficients, take their extreme values for panel 
inclination of 45 degrees. These values show small differences when compared to the cases of 40 and 30 degrees, whereas the 20-degree case experiences significantly lower values. The maximum values range from -1 to 0 and the trend of the 20-degree panel inclination experiences the lowest suction, which slightly differs from that experienced by the panel for the rest of the panel inclinations. Figures $22 \mathrm{~b}$ and $22 \mathrm{c}$ present the net peak area-averaged pressure coefficients for panels attached to $7 \mathrm{~m}$ and $16 \mathrm{~m}$ high buildings respectively. The extreme values occur for 30-degree panel inclination at the back location. Greater suction is detected for back located panels for both building heights with only exception being the 20-degree panel inclination case. For the case of front located panels when attached to $16 \mathrm{~m}$ high building, the suction experienced becomes smaller compared to that experienced by back located panels. The gradient of minimum values results in smaller suction overall, which can be reduced to almost half of the initial value. Maxima for both building heights range from -1 to 0 with slight differences among the various cases, which have a very small gradient with respect to the area.

\subsection{Code and standard provisions}

As mentioned previously in this paper, wind codes and standards do not include currently design provisions for solar panels or similar rooftop equipment. The Australian Standard (AS/NZS 1170.2, 2011) is presently considering adopting such provisions based on an experimental study carried out by Ginger et al (2011). This study investigated the wind loading applied to photovoltaic solar panels mounted on the roof of a residential and a commercial building. For the residential building, three gable-end roof models with 7.5-, 15- and 22.5-degree roof inclinations were tested at a range of different locations on the roof and fixed parallel to the roof surface at a distance 100 or $200 \mathrm{~mm}$ from it. Results indicate that panels located near the 
leading gable end of the roof are subject to large net suctions - peak $\mathrm{Cp}$, net $=-1.7$, versus values ranging from -1.2 to +0.5 for different panel roof locations. For the commercial building, a solar panel array inclined at 15 or 30 degrees was placed on top of a flat-roof building at a variety of locations. Panels inclined at 30 degrees or with an orientation such that the wind flows towards the downward inclined surface of the array, experience the largest positive and negative loads.

Some preliminary comparisons of the draft provisions with the results of the present study indicates that for the most critical cases and after transforming the peak net coefficients to the Australian context, i.e. values referenced to the dynamic velocity pressure at the roof height based on the 3-sec gust speed, results agree very well with a recommended peak $\mathrm{Cp}$, net $=-1.7$.

Finally, Fig. 23 shows a simplified diagram following the format of ASCE 7 provisions recommending design net pressure coefficient values for solar panels on ground or flat roofs. All pressure coefficients have been converted to conform to a 3-sec gust averaging period for codification purposes. The conversions were approximated by use of the Durst curve (Durst 1960). Considering all different possible geometries and configurations and the simplicity requirement, it is believed that such a diagram would be useful for the code/standard users.

\section{Conclusions}

The conclusions of this study regarding wind loads on solar panels can be summarized as follows:

- The effect of wind direction is significant: wind direction of 135 degrees is the most critical. In general, extreme values of pressure coefficients appear within the range 105 to 180 degrees.

- The effect of panel inclination is significant only for critical wind directions. 
- The effect of building height and exact panel location is not very significant for most configurations.

- Increasing building height results in smaller suction for front located panels while suction remains constant for back located panels.

- Panels near roof edges experience the greatest net force coefficient.

- Comparison of the results with some proposed values for the Australian / New Zealand standard shows good agreement. A simplified diagram for GCp coefficients appropriate for the design of solar panels on ground or on flat roofs has been proposed.

\section{Acknowledgments}

The authors acknowledge the support received for this study from the Natural Sciences and Engineering Research Council of Canada.

\section{References}

AS/NZS 1170.2, 2011. Australian/New 2 Zealand standards, structural design actions-Part 2, wind actions. Standards Australia International Ltd.-Standards New Zealand.

Bienkiewicz, B., Endo, M., 2009. Wind considerations for loose-laid and photovoltaic roofing systems. Structures Congress - ASCE, Austin, TX, USA.

Bronkhorst, A. J., Geurts, C. P., Bentum, C. V., Grepinet, F., 2010. Wind tunnel and CFD modelling of wind pressures on solar energy systems on flat roofs. 5th International Symposium on Computational Wind Engineering (CWE2010), Chapel Hill, NC, USA.

Durst, C.S., 1960. Wind speeds over short periods of time. Meteorological Magazine. 89, 181186. 
Erwin, J., Gan Chowdhury, A., Bitsuamlak, G.T., Guerra, C., 2011. Wind effects on photovoltaic panels mounted on residential roofs. 13th International Conference on Wind Engineering (ICWE13), Amsterdam, Netherlands.

Ginger, J., Payne, M., Stark, G., Sumant, B., Leitch, C., 2011. Investigation on wind loads applied to solar panels mounted on roofs - Report No. TS821. Cyclone Testing Station, School of Engineering \& Physical Sciences, James Cook University, Townsville, Australia.

Hosoya, N., Cermak, J. E., Steele, C., 2001. A Wind-tunnel study of a cubic rooftop AC unit on a low building. 9th Americas Conference on Wind Engineering (ACWE), Clemson, SC, USA.

Kopp, G., Banks, D., 2013. Use of the wind tunnel test method for obtaining design wind loads on roof-mounted solar arrays. Journal of Structural Engineering, ASCE, 139, 284-287.

Maffei, J., Telleen, K., Ward, R., Kopp, G., SchellenbergA., 2013. Wind design practice and recommendations for solar arrays on low-slope roofs. Journal of Structural Engineering, ASCE, in print.

Radu, A., Axinte, E., 1989. Wind forces on structures supporting solar collectors. Journal of Wind Engineering and Industrial Aerodynamics, 32(1-2), 93-100.

Radu, A., Axinte, E., Theohari, C., 1986. Steady wind pressures on solar collectors on flat-roofed buildings. Journal of Wind Engineering and Industrial Aerodynamics, 23, 249-258.

Ruscheweyh, H., Windhövel, R., 2011. Wind loads at solar and photovoltaic modules for large plants. 13th International Conference on Wind Engineering (ICWE13), Amsterdam, Netherlands.

Saha, P. K., Yoshida, A., Tamura, Y., 2011. Study on wind loading on solar panel on a flat-roof building: Effects of locations and inclination angles. 13th International Conference on Wind Engineering (ICWE13), Amsterdam, Netherlands. 
Stathopoulos, T., Zisis, I., Xypnitou, E., 2012. Wind loads on solar collectors: A review. Structures Congress - ASCE, Chicago, IL, USA.

Stenabaugh, S. E., Karava, P., Kopp, G. A., 2011. Design wind loads for photovoltaic systems on sloped roofs of residential buildings. 13th International Conference on Wind Engineering, Amsterdam, Netherlands.

Tieleman, H.W., Reinhold, T.A., Marshall, R.D., 1978. On the wind-tunnel simulation of the atmospheric surface layer for the study of wind loads on low-rise buildings. Journal of Wind Engineering and Industrial Aerodynamics, Vol. 3, 21-38.

Tieleman, H.W., Reinhold, T.A., Hajj, M.R., 1997. Importance of turbulence for the prediction of surface pressures on low-rise structures. Journal of Wind Engineering and Industrial Aerodynamics, Vol. 69-71, 519-528.

Tieleman, H.W., Hajj, M.R., Reinhold, T.A., 1998. Wind tunnel simulation requirements to assess wind loads on low-rise buildings. Journal of Wind Engineering and Industrial Aerodynamics, Vol. 74-76, 675-685.

Wang, K. and Stathopoulos, T., 2006. The impact of exposure on wind loading of low buildings. SEI-ASCE Structures Congress, May 18-20, St. Louis, MO, USA.

Wood, G.S., Denoon, R., Kwok, K., 2001. Wind loads on industrial solar panel arrays and supporting roof structure. Wind and Structures, 4(6), 481-494.

Xypnitou, E., 2012. Wind loads on solar panel systems attached to building roofs. MASc Thesis, Concordia University, Montreal, QC, Canada. 


\section{List of Figure Captions}

Figure 1. Configurations of photovoltaic systems considered for comparison to current study.

Figure 2. Comparison of peak force coefficients for 15-degree panel inclination for the Erwin et al. (2011) and Saha et al. (2011) studies.

Figure 3. Examples of (a) ground-mounted and (b) roof-mounted solar panel systems.

Figure 4. Wind tunnel building model with solar panels.

Figure 5. Top view of the building roof with solar panels attached on the front location indicating the pressure tap notation (odd and even numbers denote upper and lower surface respectively).

Figure 6. (a) Front and (b) back located panels with model -scale dimensions.

Figure 7. Peak pressure coefficients on (a) upper and (b) lower surface for 135-degree wind direction.

Figure 8. Net peak pressure coefficients for 135-degree wind direction.

Figure 9. (a) upper, (b) lower surface peak pressure coefficients and (c) net peak pressure coefficients for front location and 135-degree wind direction.

Figure 10. (a) upper, (b) lower surface peak pressure coefficients and (c) net peak pressure coefficients for back location and 135-degree wind direction.

Figure 11. Net peak pressure coefficients for ground level panels with respect to wind direction.

Figure 12. Net peak pressure coefficients for panels attached to the roof of a (a) $7 \mathrm{~m}$ and (b) $16 \mathrm{~m}$ high building for front and back location.

Figure 13. Net peak force coefficients for 135-degree wind direction applied on stand-alone panels.

Figure 14. Net minimum force coefficients for 135-degree wind direction applied on panels attached to the roof of a (a) $7 \mathrm{~m}$ and (b) $16 \mathrm{~m}$ high building for front and back location. 
Figure 15. Net maximum force coefficients for 135-degree wind direction applied on panels attached to the roof of a (a) $7 \mathrm{~m}$ and (b) $16 \mathrm{~m}$ high building for front and back location.

Figure 16. Net (a) minimum and (b) maximum force coefficients for 135-degree wind direction, applied on 3 panels for front location.

Figure 17. Net (a) minimum and (b) maximum force coefficients for 135-degree wind direction, applied on 3 panels for back location.

Figure 18. Net peak force coefficients for stand-alone (a) panel 1, (b) panel 2 and (c) panel 3.

Figure 19. Net peak force coefficients for (a) panel 1, (b) panel 2 and (c) panel 3 when attached to $7 \mathrm{~m}$ high building, front and back location.

Figure 20. Net peak force coefficients for (a) panel 1, (b) panel 2 and (c) panel 3 when attached to $16 \mathrm{~m}$ high building, front and back location.

Figure 21. Comparison of local Cp and panel Cf for (a) 20-, (b) 30-, (c) 40- and (d) 45-degree panel inclination for $7 \mathrm{~m}$ high building and front location.

Figure 22. Net peak area-averaged pressure coefficients for panels (a) stand-alone, (b) attached to $7 \mathrm{~m}$ high building and (c) attached to $16 \mathrm{~m}$ building considering 135-degree wind direction.

Figure 23. Simplified provisions (ASCE 7 format) for the design of solar panels on roofs or on ground. 

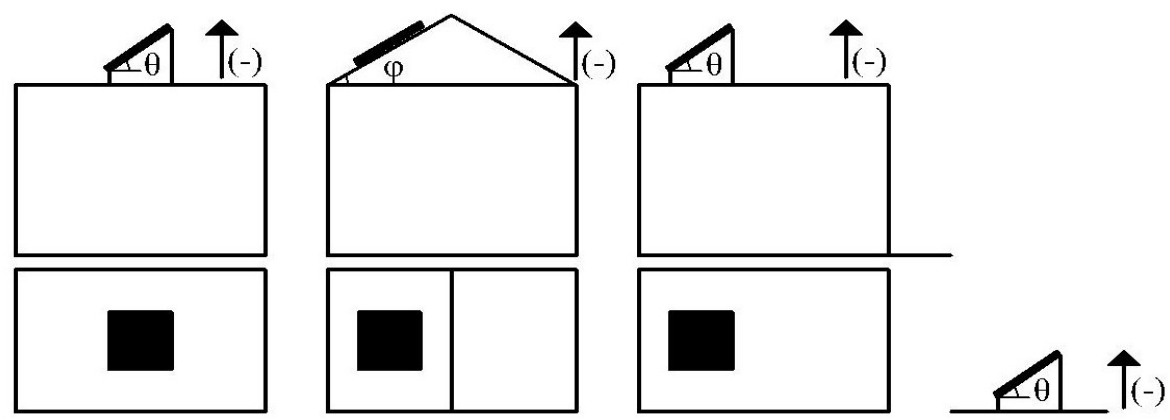

Figure 1. Configurations of photovoltaic systems considered for comparison to current study.

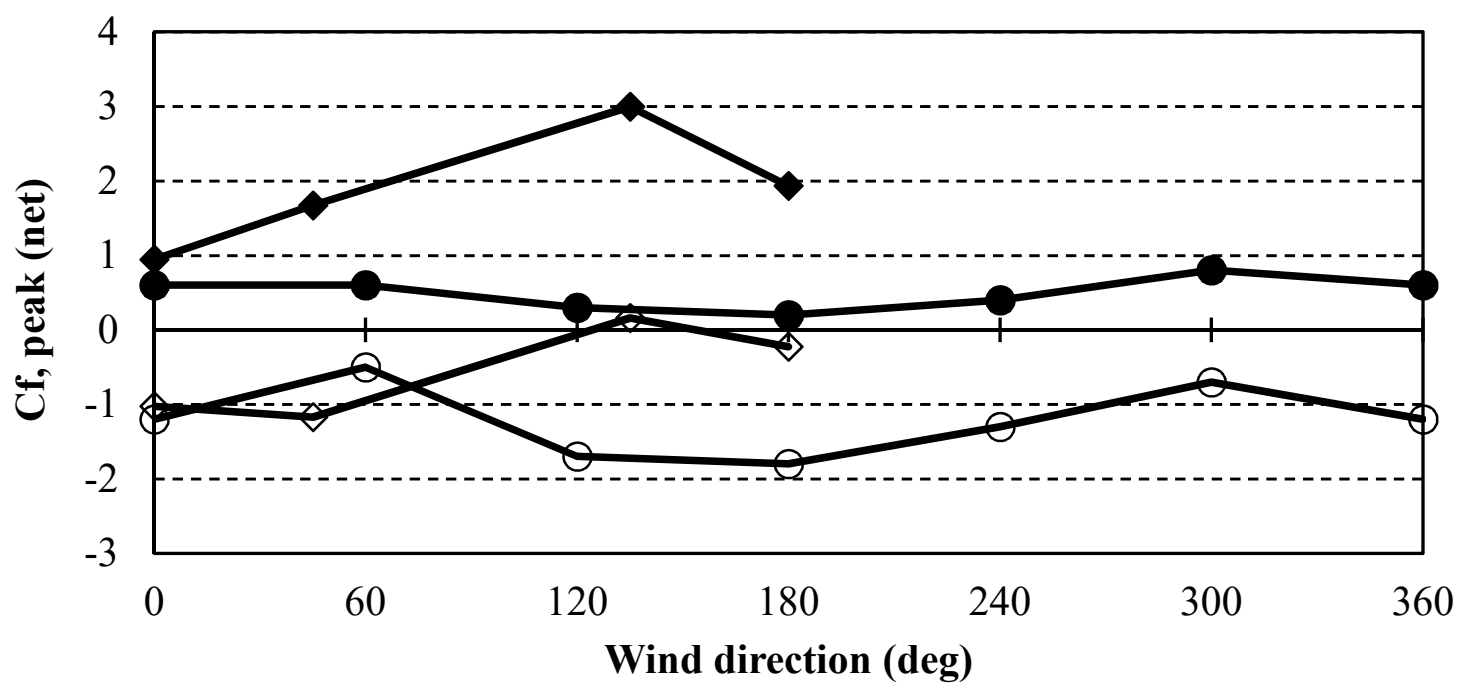

Erwin et al. (2011) $\leadsto$ max $\curvearrowright$ min

Saha et al. (2011) -max $\curvearrowright$ min

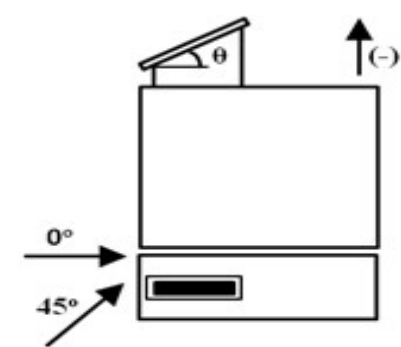

Figure 2. Comparison of peak force coefficients for 15-degree panel inclination for the Erwin et al. (2011) and Saha et al. (2011) studies. 
(a)

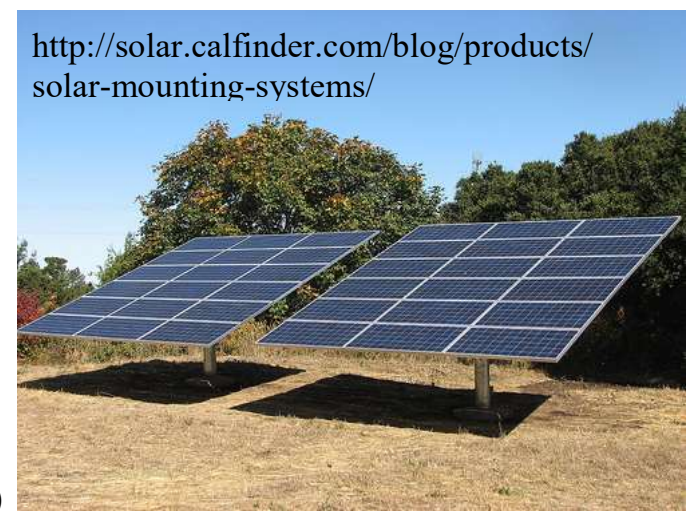

(b)

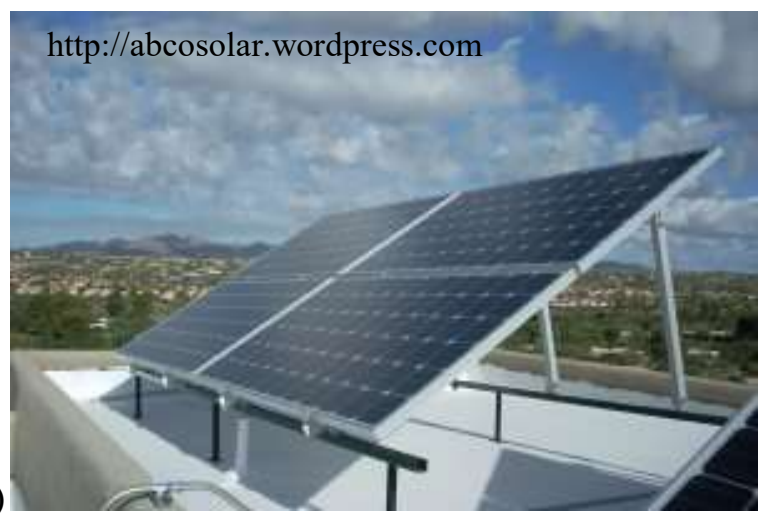

Figure 3. Examples of (a) ground-mounted and (b) roof-mounted solar panel systems.

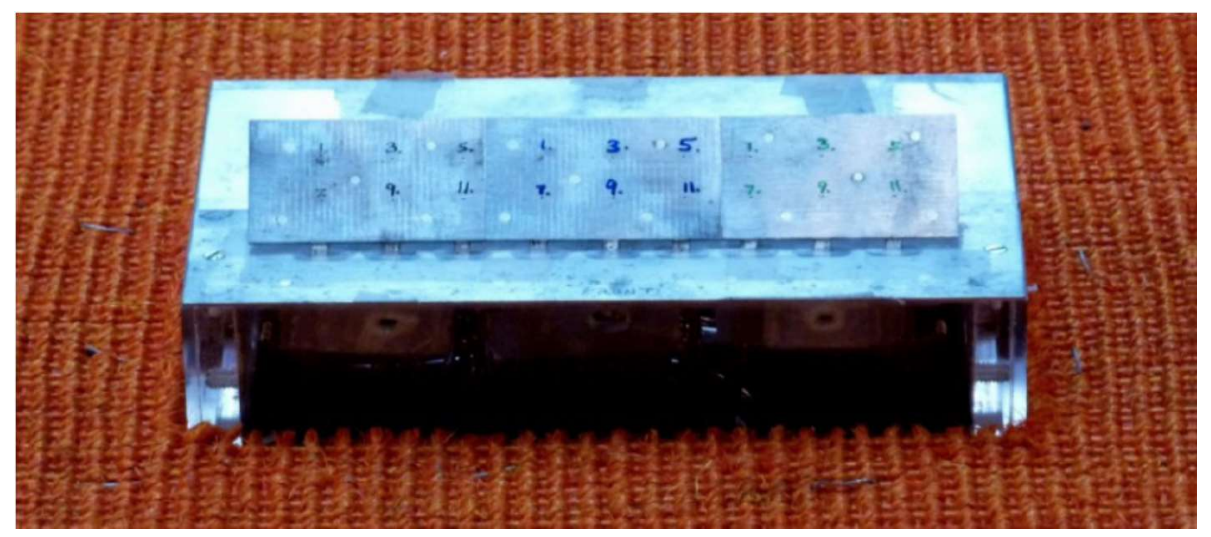

Figure 4. Wind tunnel building model with solar panels. 


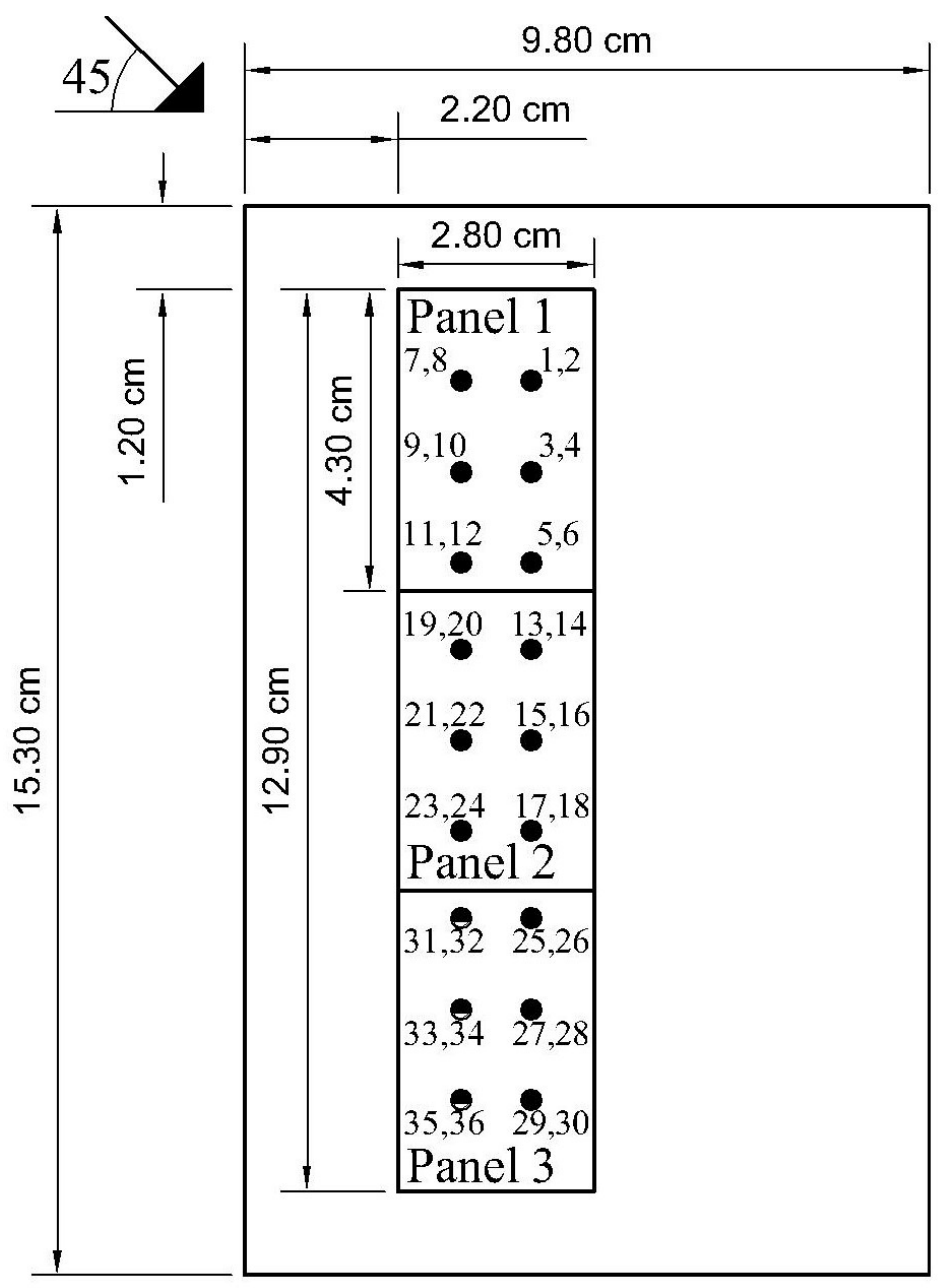

Figure 5. Top view of the building roof with solar panels attached on the front location indicating the pressure tap notation (odd and even numbers denote upper and lower surface respectively). 


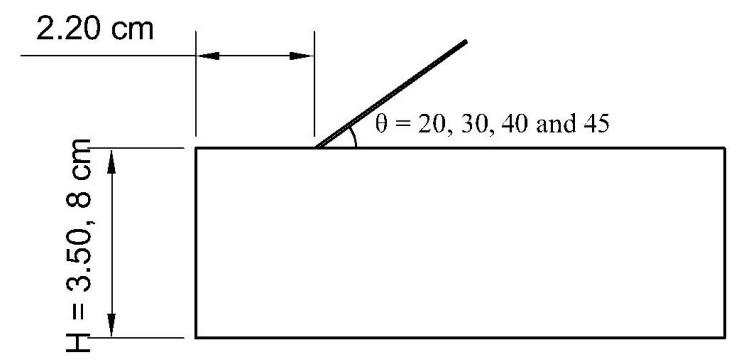

(a)

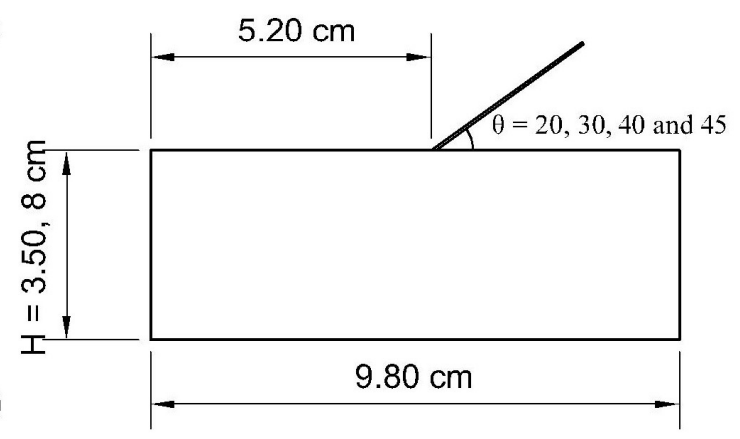

Figure 6. (a) Front and (b) back located panels with model-scale dimensions. 

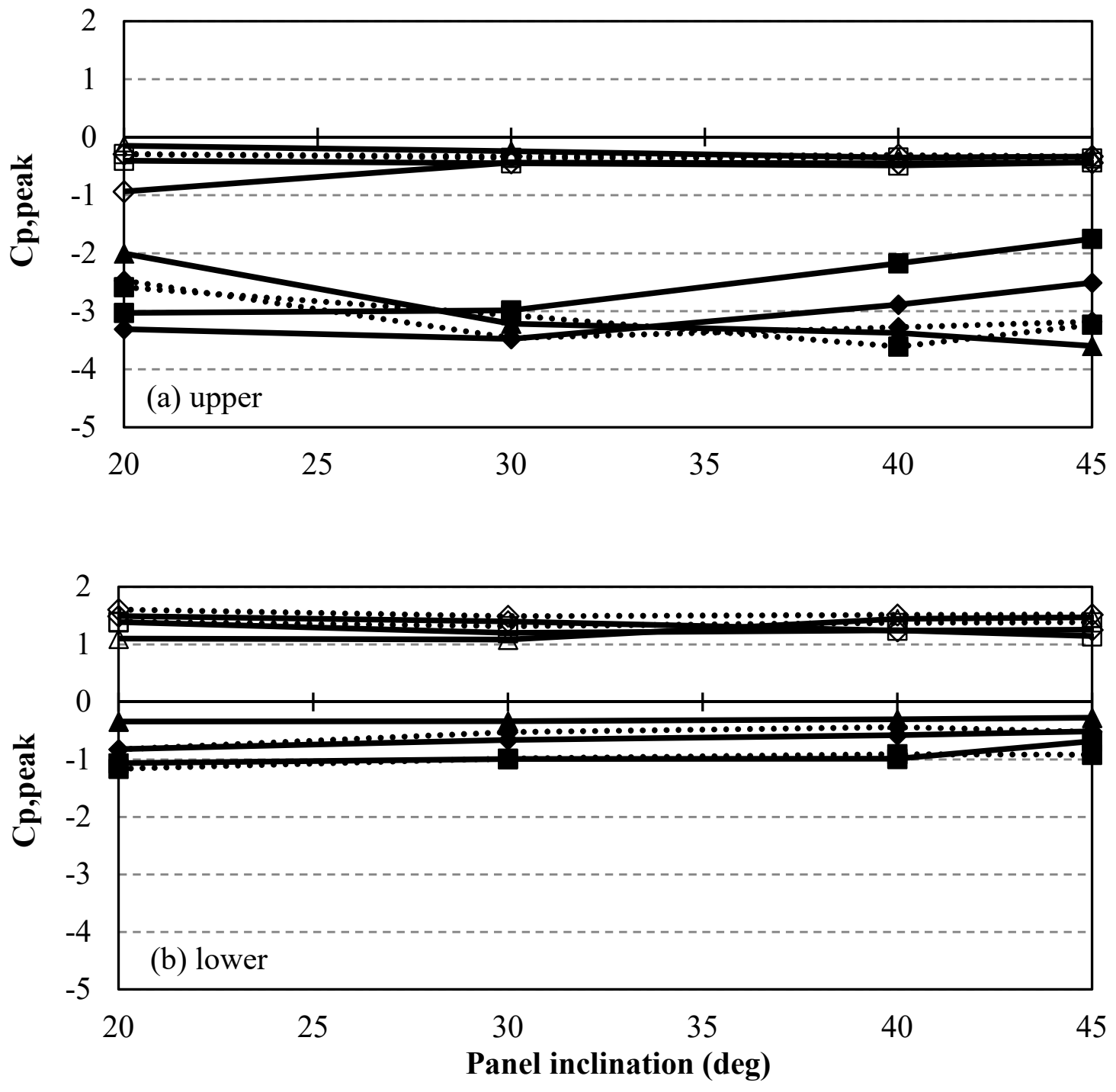

\begin{tabular}{|c|c|c|c|c|c|}
\hline \multirow{3}{*}{ Minimum } & \multicolumn{5}{|c|}{ Building height } \\
\hline & \multirow{2}{*}{$\frac{\text { Ground }}{\not-0 \mathrm{~m}}$} & \multicolumn{2}{|c|}{ Front } & \multicolumn{2}{|c|}{ Back } \\
\hline & & $\leadsto 7 \mathrm{~m}$ & $-16 \mathrm{~m}$ & $\bullet \diamond \cdot \cdot 7 \mathrm{~m}$ & $\cdot . \cdot \cdot 16 \mathrm{~m}$ \\
\hline Maximum & $\triangle 0 \mathrm{~m}$ & $\approx 7 \mathrm{~m}$ & $-16 \mathrm{~m}$ & $\cdots \diamond \cdot \cdots 7 \mathrm{~m}$ & $\bullet \bullet \cdot 16 \mathrm{~m}$ \\
\hline
\end{tabular}

Figure 7. Peak pressure coefficients on (a) upper and (b) lower surface for 135-degree wind direction. 


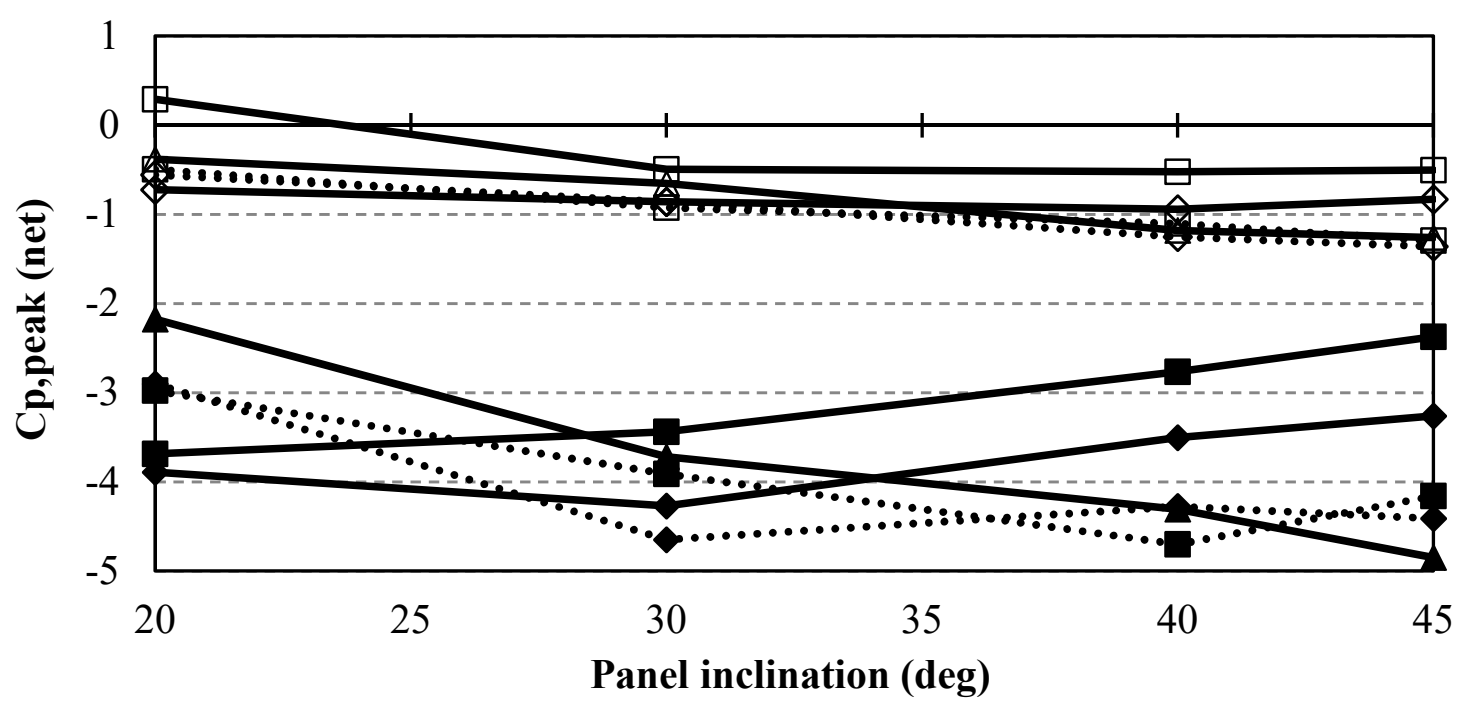

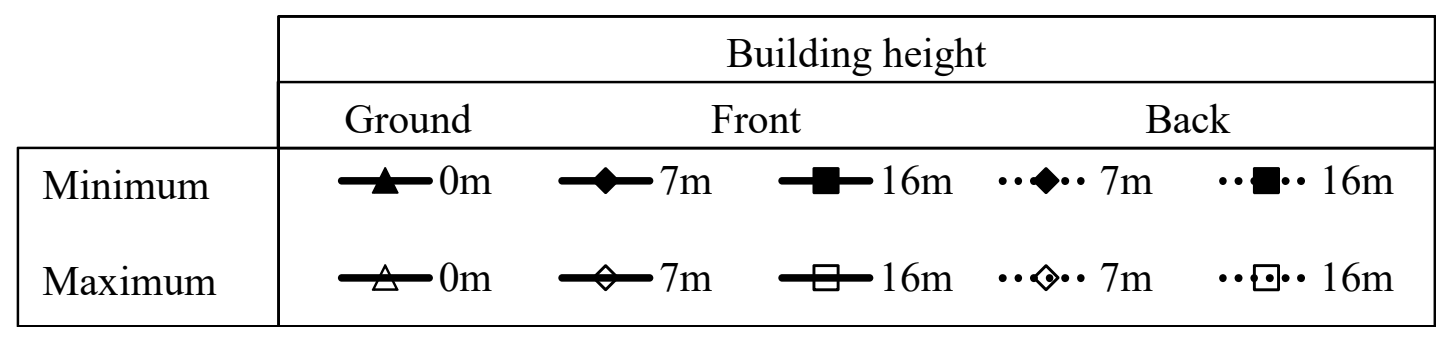

Figure 8. Net peak pressure coefficients for 135-degree wind direction. 

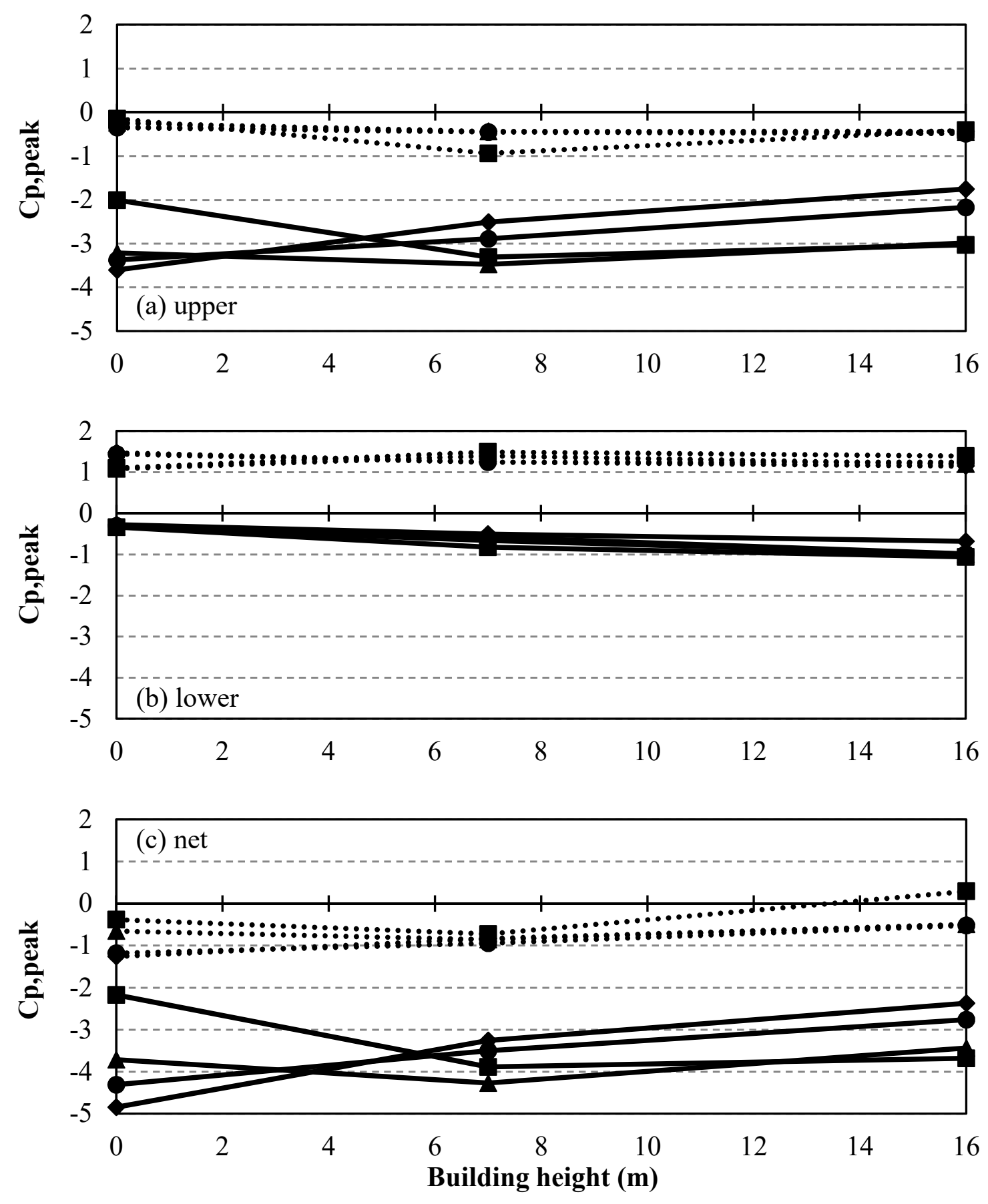

\begin{tabular}{|c|c|c|c|c|}
\hline & \multicolumn{4}{|c|}{ Panel Inclination (deg) } \\
\hline Minimum & $\rightarrow-20$ & -30 & $\rightarrow 40$ & $\neg 45$ \\
\hline Maximum & •.• $\cdot \cdot 20$ & $\cdots \star \bullet \cdot 30$ & $\cdot \bullet \bullet \cdot \cdot 40$ & $\cdots \bullet \bullet 45$ \\
\hline
\end{tabular}

Figure 9. (a) upper, (b) lower surface peak pressure coefficients and (c) net peak pressure coefficients for front location and 135-degree wind direction. 

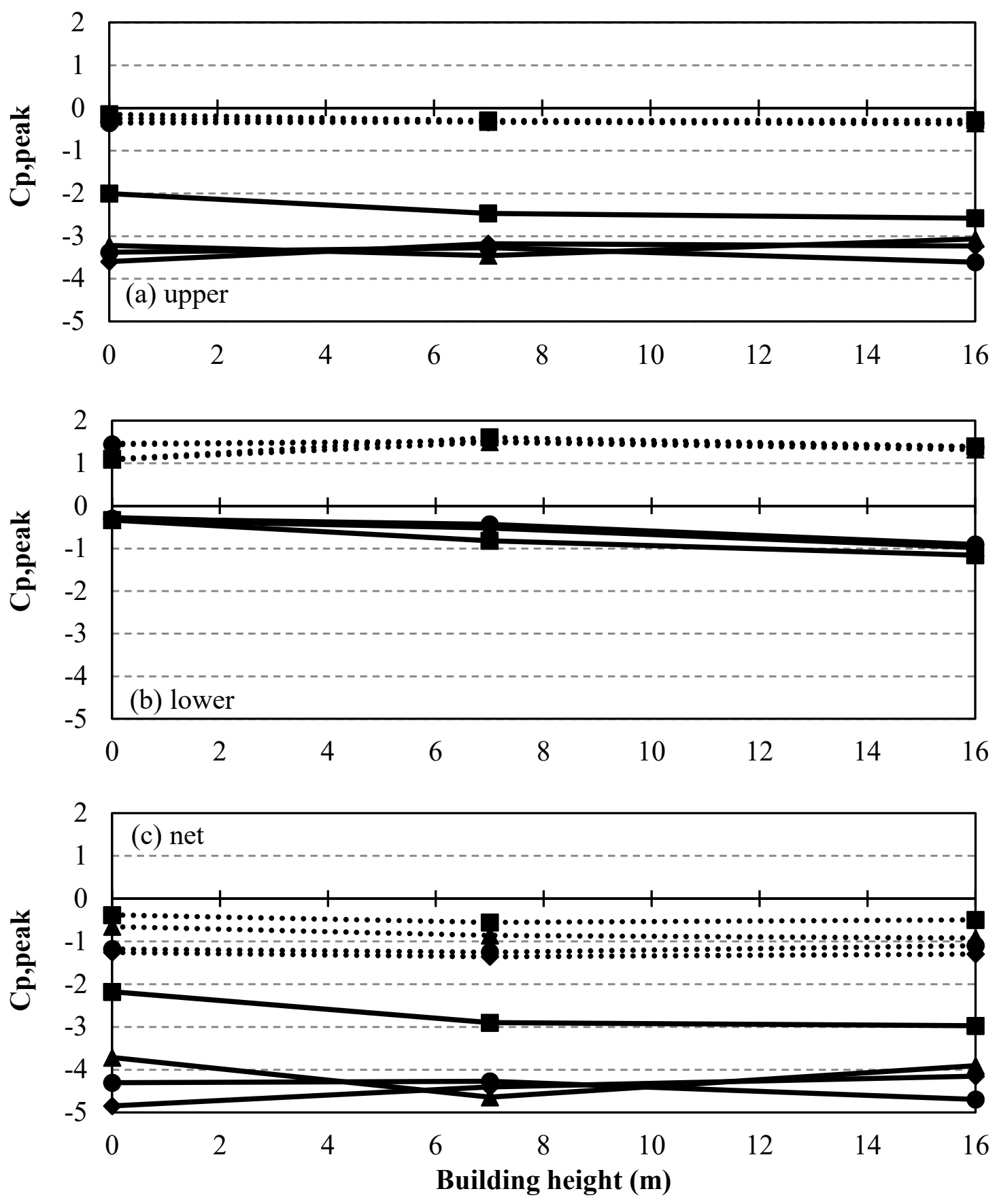

\begin{tabular}{|c|c|c|c|c|}
\hline & \multicolumn{4}{|c|}{ Panel Inclination (deg) } \\
\hline Minimum & -20 & $-1-30$ & -40 & $\neg-45$ \\
\hline Maximum & ・・日. 20 & $\cdot \bullet \Delta \cdot \bullet 30$ & $\cdots 40$ & $\bullet \diamond \bullet 45$ \\
\hline
\end{tabular}

Figure 10. (a) upper, (b) lower surface peak pressure coefficients and (c) net peak pressure coefficients for back location and 135-degree wind direction. 


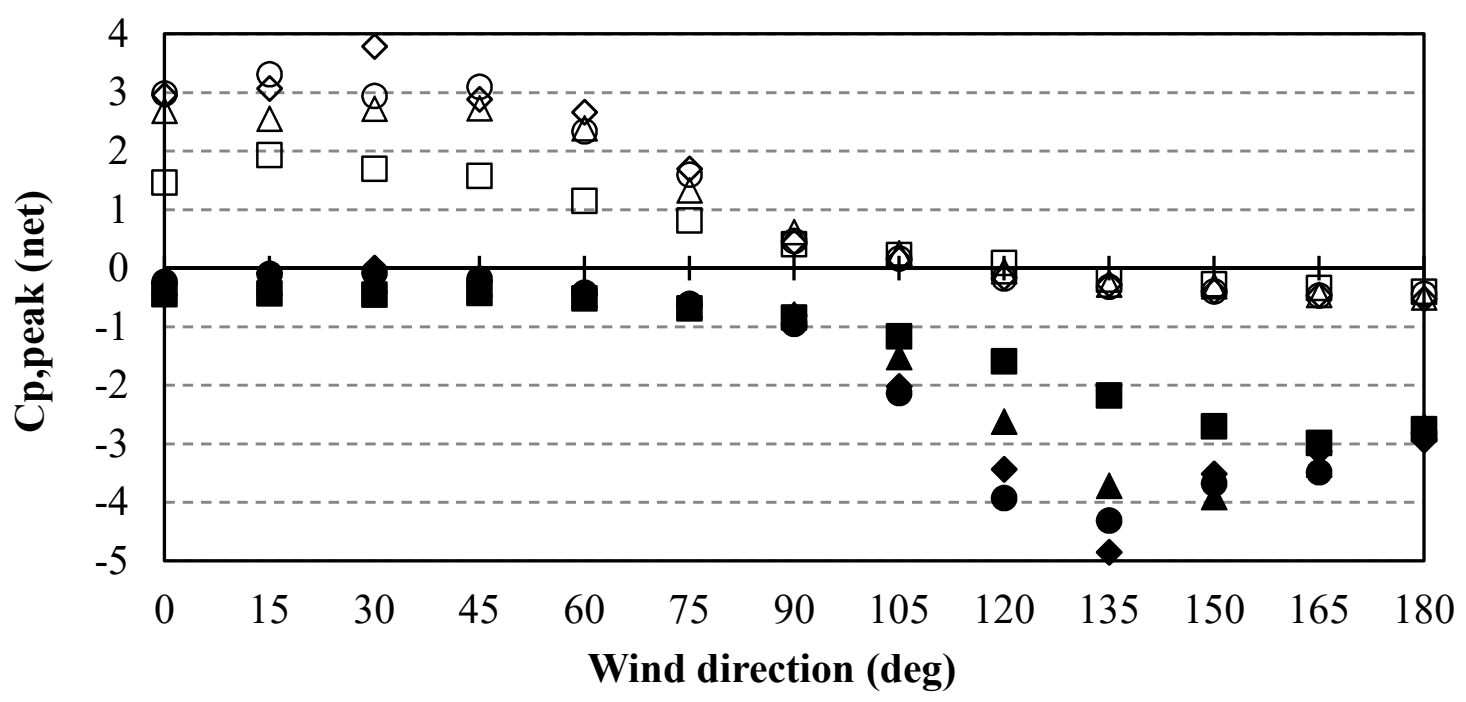

\begin{tabular}{|l|cccc|}
\cline { 2 - 3 } \multicolumn{1}{c|}{} & \multicolumn{4}{c|}{ Panel inclination $(\mathrm{deg})$} \\
\hline Minimum & $\square 20$ & $\Delta 30$ & $\bullet 40$ & $\diamond 45$ \\
Maximum & $\square 20$ & $\triangle 30$ & $\bigcirc 40$ & $\diamond 45$ \\
\hline
\end{tabular}

Figure 11. Net peak pressure coefficients for ground level panels with respect to wind direction. 

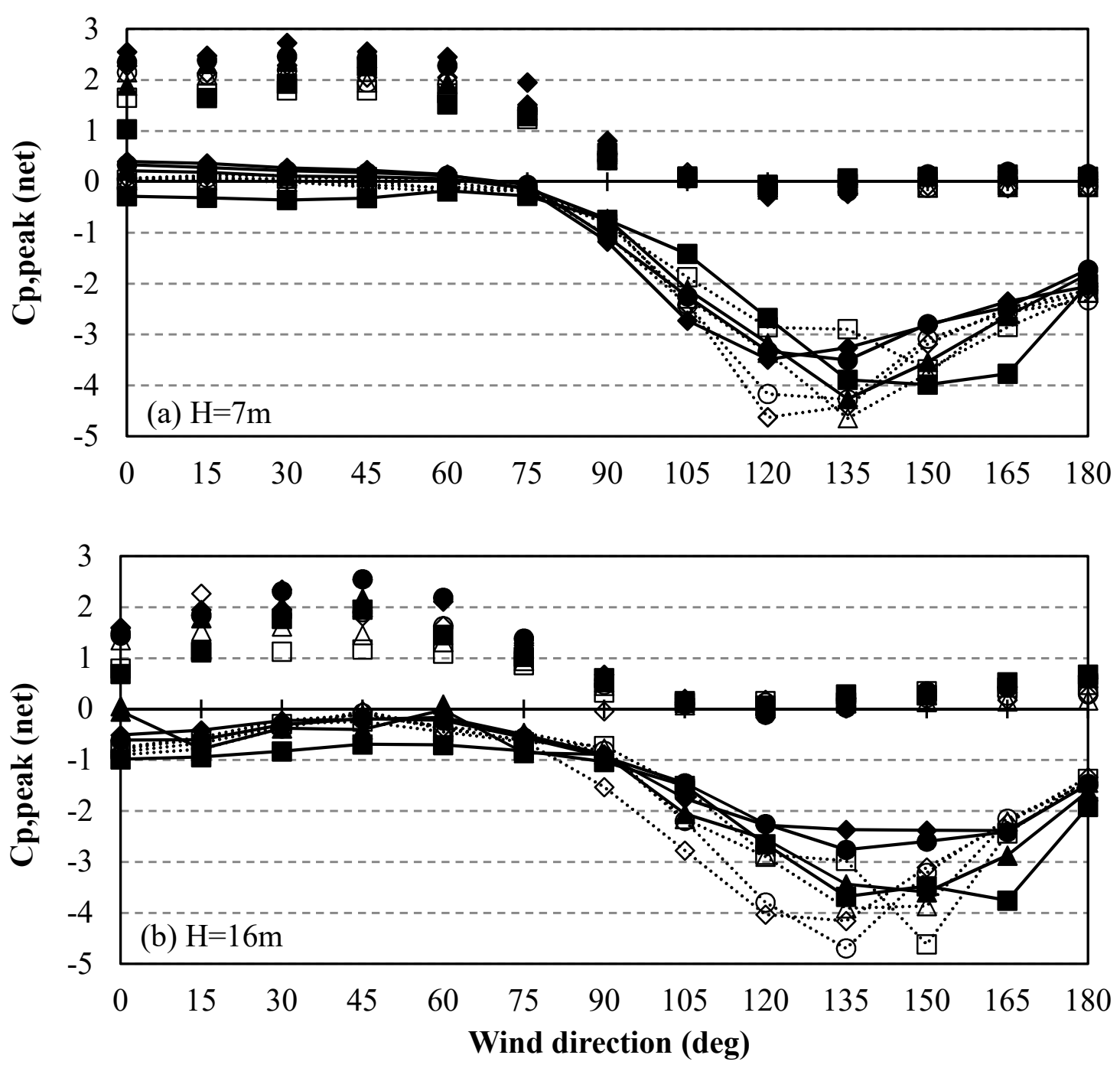

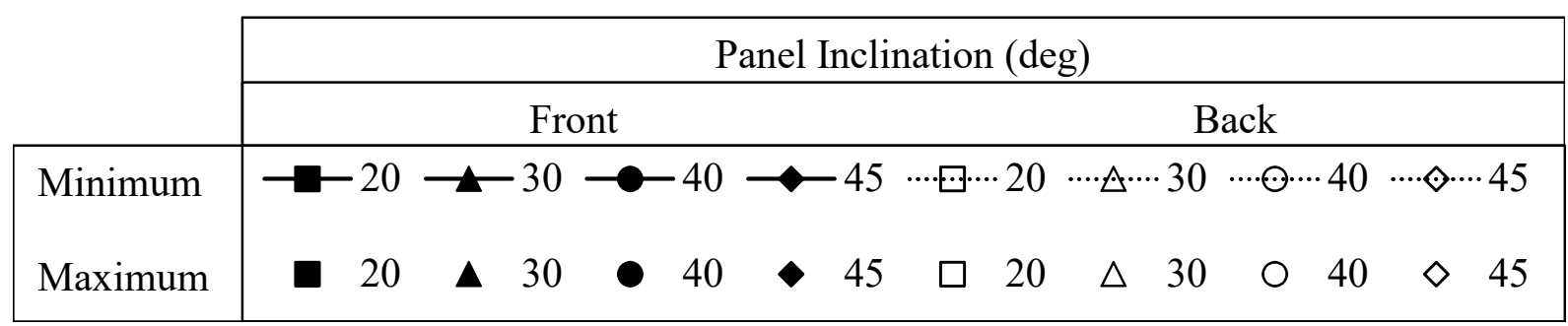

Figure 12. Net peak pressure coefficients for panels attached to the roof of a (a) $7 \mathrm{~m}$ and (b) $16 \mathrm{~m}$ high building for front and back location. 


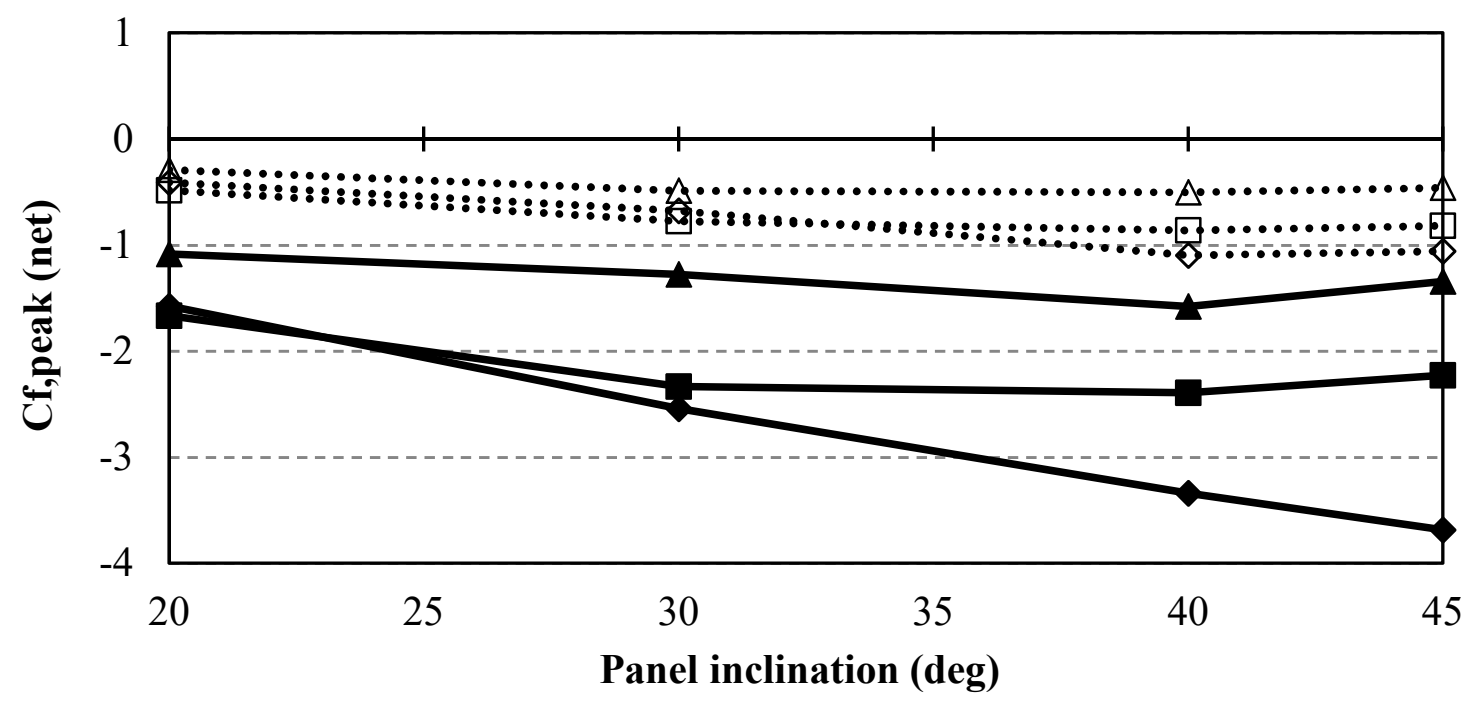

\begin{tabular}{|l|lll|}
\hline Minimum & $\sim$ panel 1 & $\rightarrow$ panel 2 & $\rightarrow$ panel 3 \\
Maximum & $\cdots \diamond \cdot$ panel 1 & $\cdots \bullet$ panel 2 & $\cdots \bullet \cdot$ panel 3 \\
\hline
\end{tabular}

Figure 13. Net peak force coefficients for 135-degree wind direction applied on stand-alone panels. 

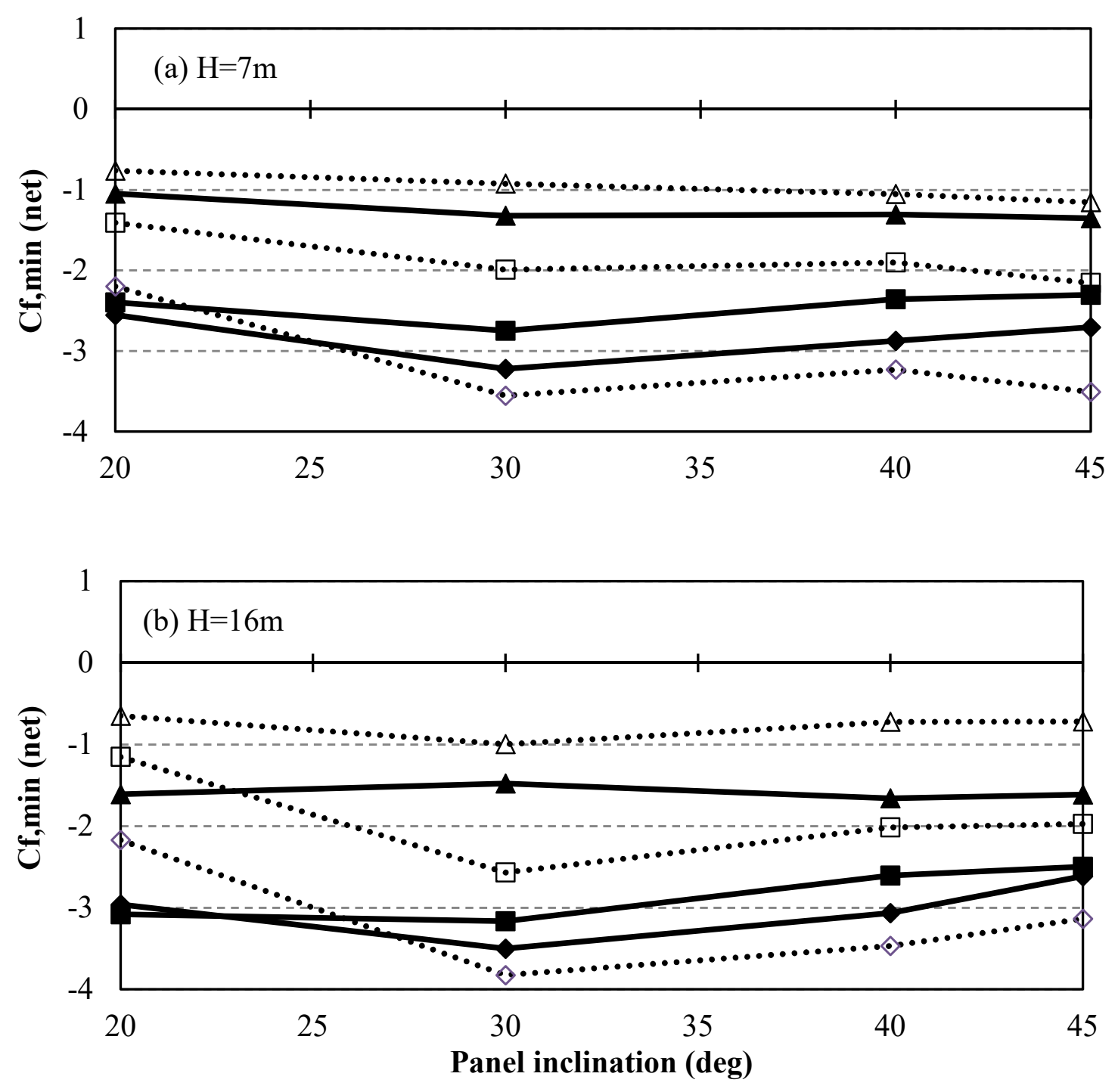

\begin{tabular}{|c|c|c|c|}
\hline Front & $\leadsto$ panel 1 & $\rightarrow$ panel 2 & 工-panel 3 \\
\hline Back &.$\leftrightarrow \cdot$ panel 1 & .๑. panel 2 & $\cdots \Delta \cdot$ panel 3 \\
\hline
\end{tabular}

Figure 14. Net minimum force coefficients for 135-degree wind direction applied on panels attached to the roof of a (a) $7 \mathrm{~m}$ and (b) $16 \mathrm{~m}$ high building for front and back location. 

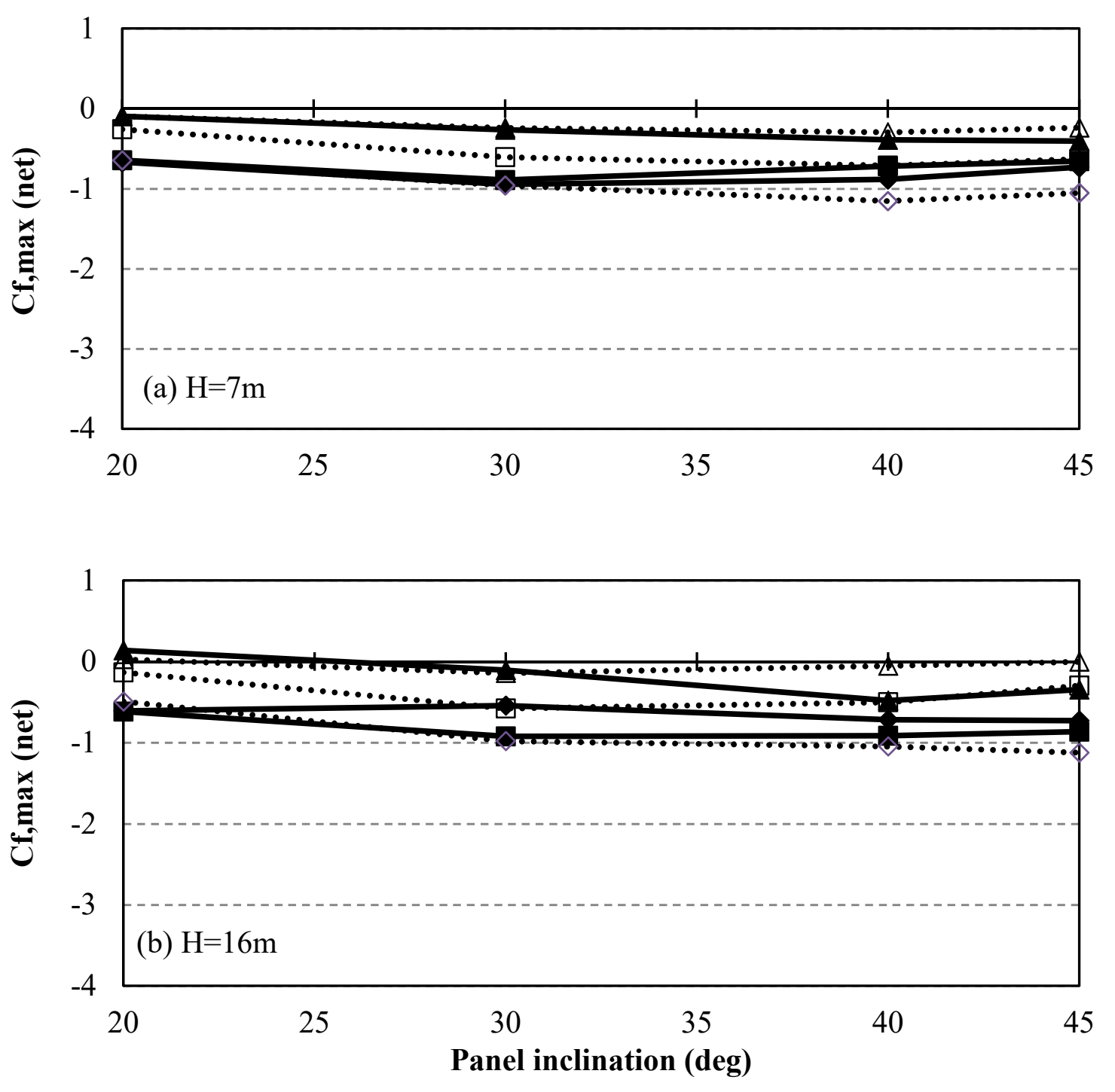

\begin{tabular}{|c|c|c|c|}
\hline Front & $\sim$ panel 1 & $\longrightarrow$ panel 2 & $\longrightarrow$ panel 3 \\
\hline Back & 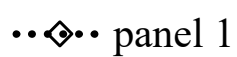 & •も.• panel 2 & ••A.•panel 3 \\
\hline
\end{tabular}

Figure 15. Net maximum force coefficients for 135-degree wind direction applied on panels attached to the roof of a (a) $7 \mathrm{~m}$ and (b) $16 \mathrm{~m}$ high building for front and back location. 

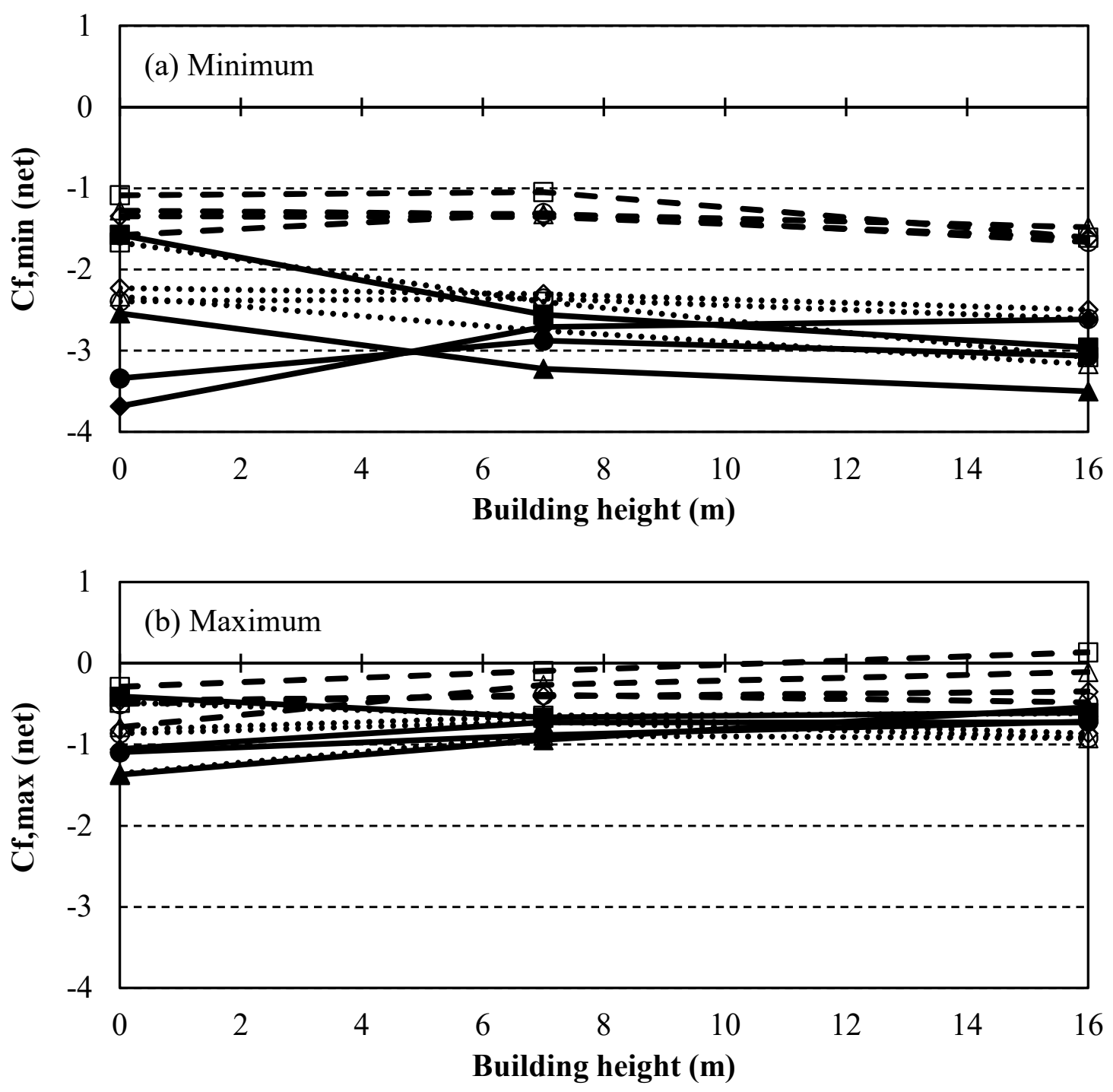

\begin{tabular}{|c|c|c|c|c|}
\hline & \multicolumn{4}{|c|}{ Panel inclination (deg) } \\
\hline Panel 1 & $\rightarrow-20$ & -30 & $\rightarrow 40$ & $\longrightarrow 45$ \\
\hline Panel 2 & $\because \bullet \cdot 20$ & $\cdots \Delta \cdot \cdot 30$ &.$\odot 40$ &.$\diamond \diamond \cdot 45$ \\
\hline Panel 3 & $-\square-20$ & $-\Delta-30$ & $-\odot-40$ & $-\diamond 45$ \\
\hline
\end{tabular}

Figure 16. Net (a) minimum and (b) maximum force coefficients for 135-degree wind direction, applied on 3 panels for front location. 

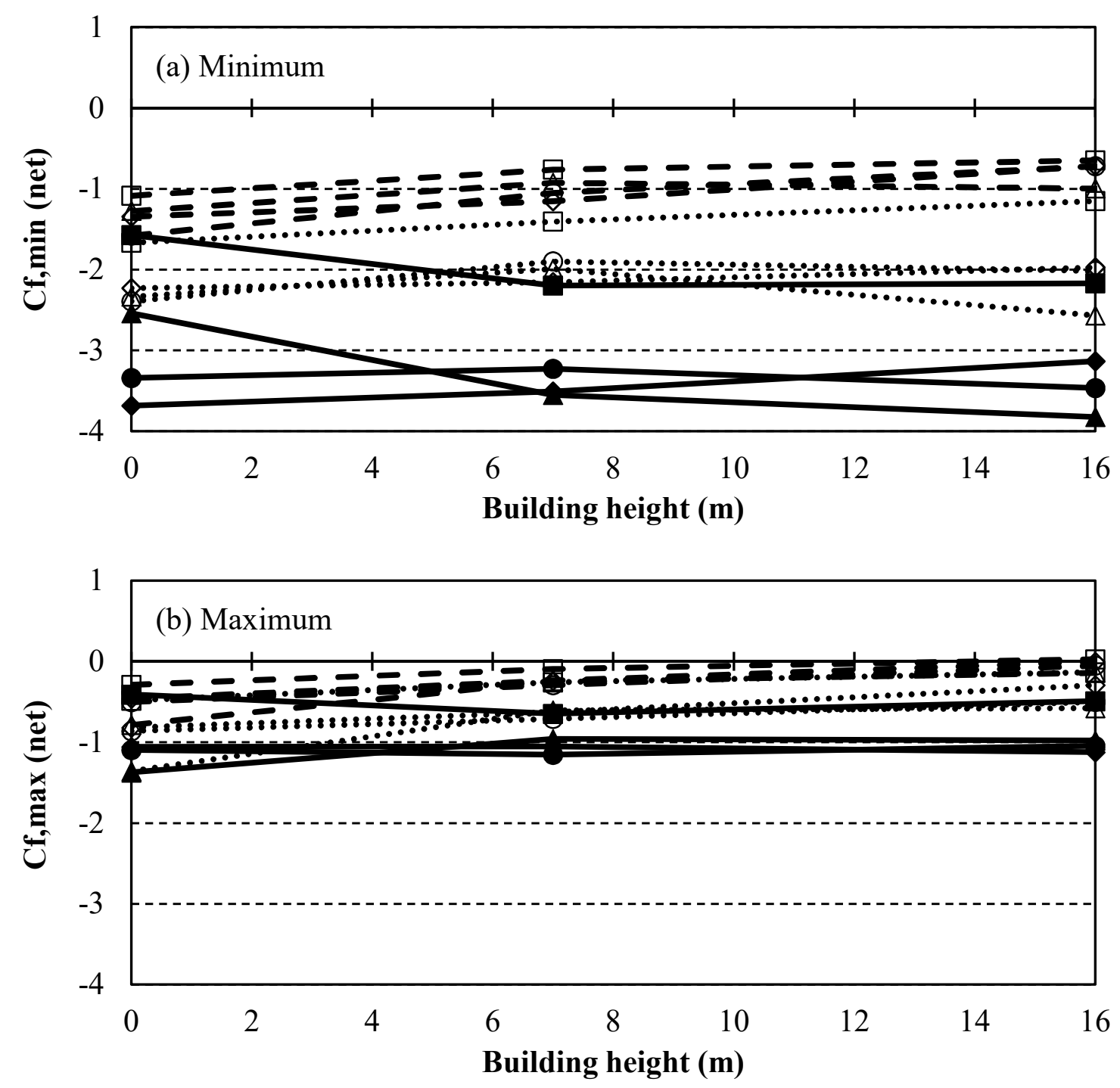

\begin{tabular}{|c|c|c|c|c|}
\hline & \multicolumn{4}{|c|}{ Panel inclination (deg) } \\
\hline Panel 1 & $\rightarrow-20$ & -30 & $\rightarrow 40$ & $\longrightarrow 45$ \\
\hline Panel 2 & $\because \bullet \cdot 20$ & $\cdots \Delta \cdot \cdot 30$ &.$\odot 40$ &.$\diamond \diamond \cdot 45$ \\
\hline Panel 3 & $-\square-20$ & $-\Delta-30$ & $-\odot-40$ & $-\diamond 45$ \\
\hline
\end{tabular}

Figure 17. Net (a) minimum and (b) maximum force coefficients for 135-degree wind direction, applied on 3 panels for back location. 

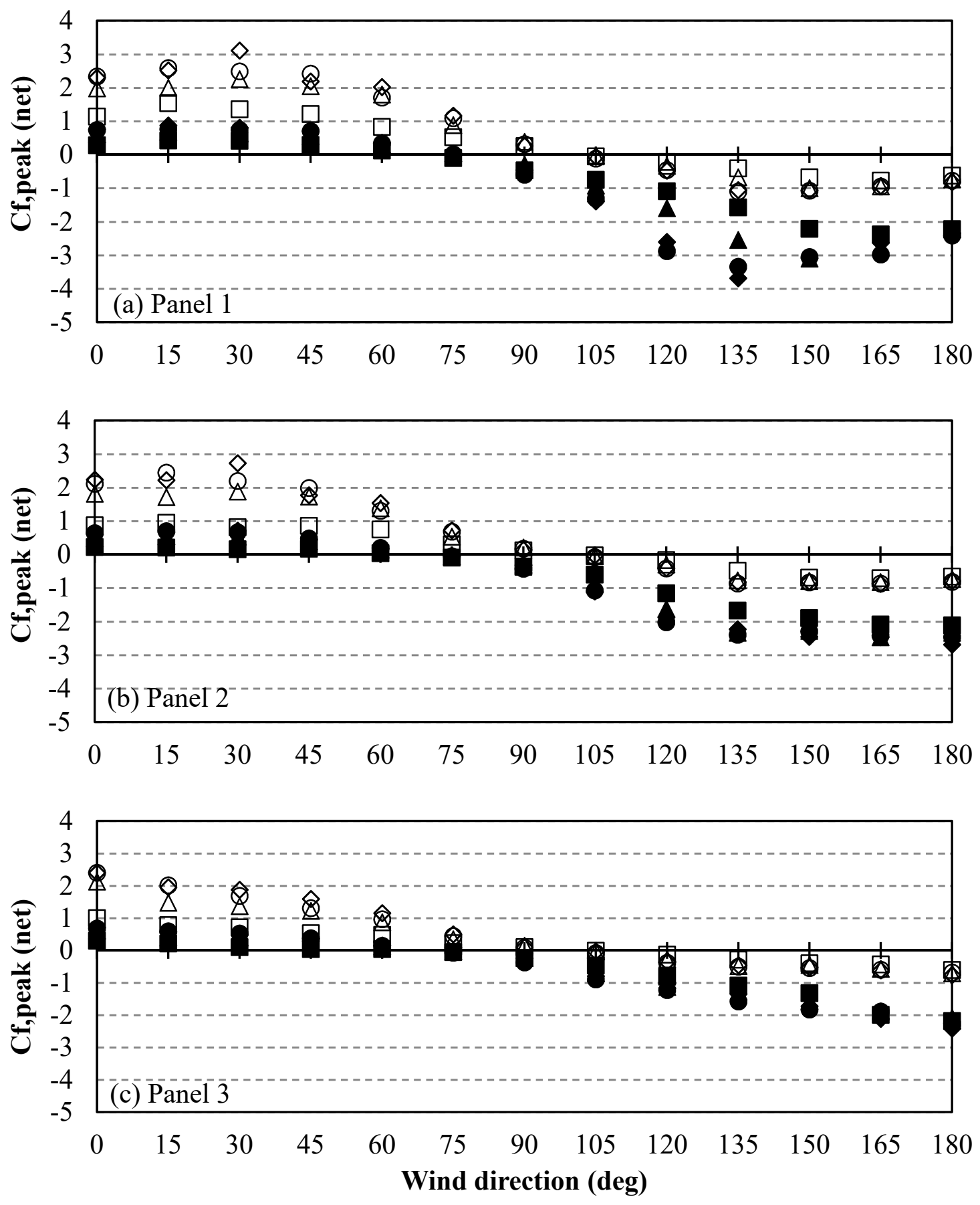

\begin{tabular}{|l|cccc|}
\cline { 2 - 3 } \multicolumn{1}{c|}{} & \multicolumn{4}{c|}{ Panel inclination $(\mathrm{deg})$} \\
\hline Minimum & $\mathbf{\square} 20$ & $\mathbf{\Delta 3 0}$ & $\bullet 40$ & $\diamond 45$ \\
Maximum & $\square 20$ & $\triangle 30$ & $\bigcirc 40$ & $\diamond 45$ \\
\hline
\end{tabular}

Figure 18. Net peak force coefficients for stand-alone (a) panel 1, (b) panel 2 and (c) panel 3. 

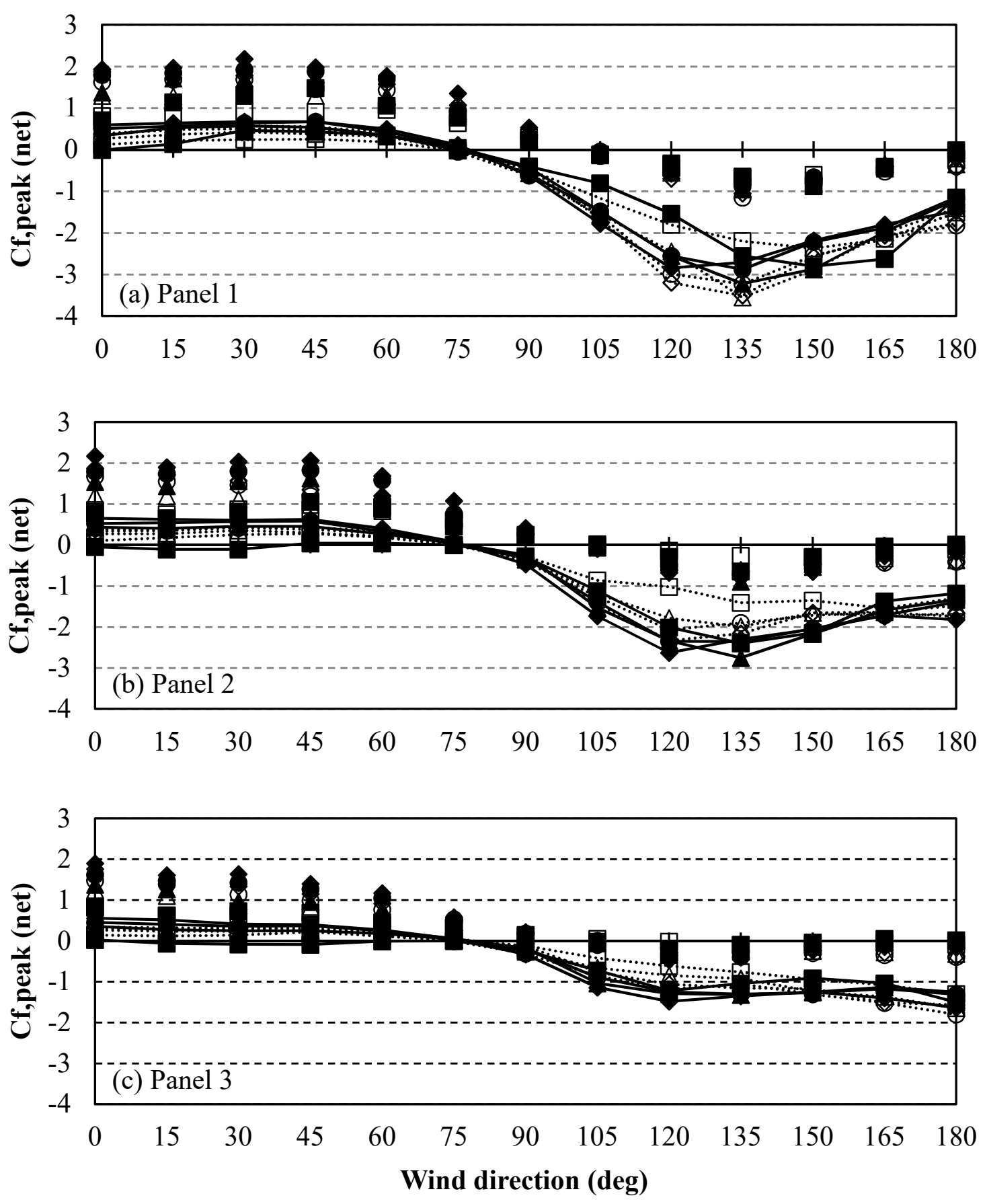

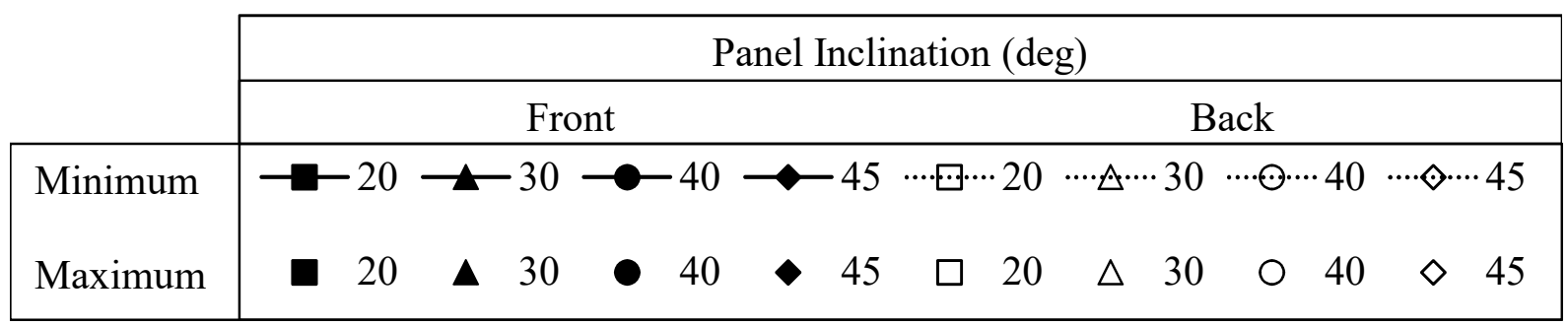

Figure 19. Net peak force coefficients for (a) panel 1, (b) panel 2 and (c) panel 3 when attached to $7 \mathrm{~m}$ high building, front and back location. 

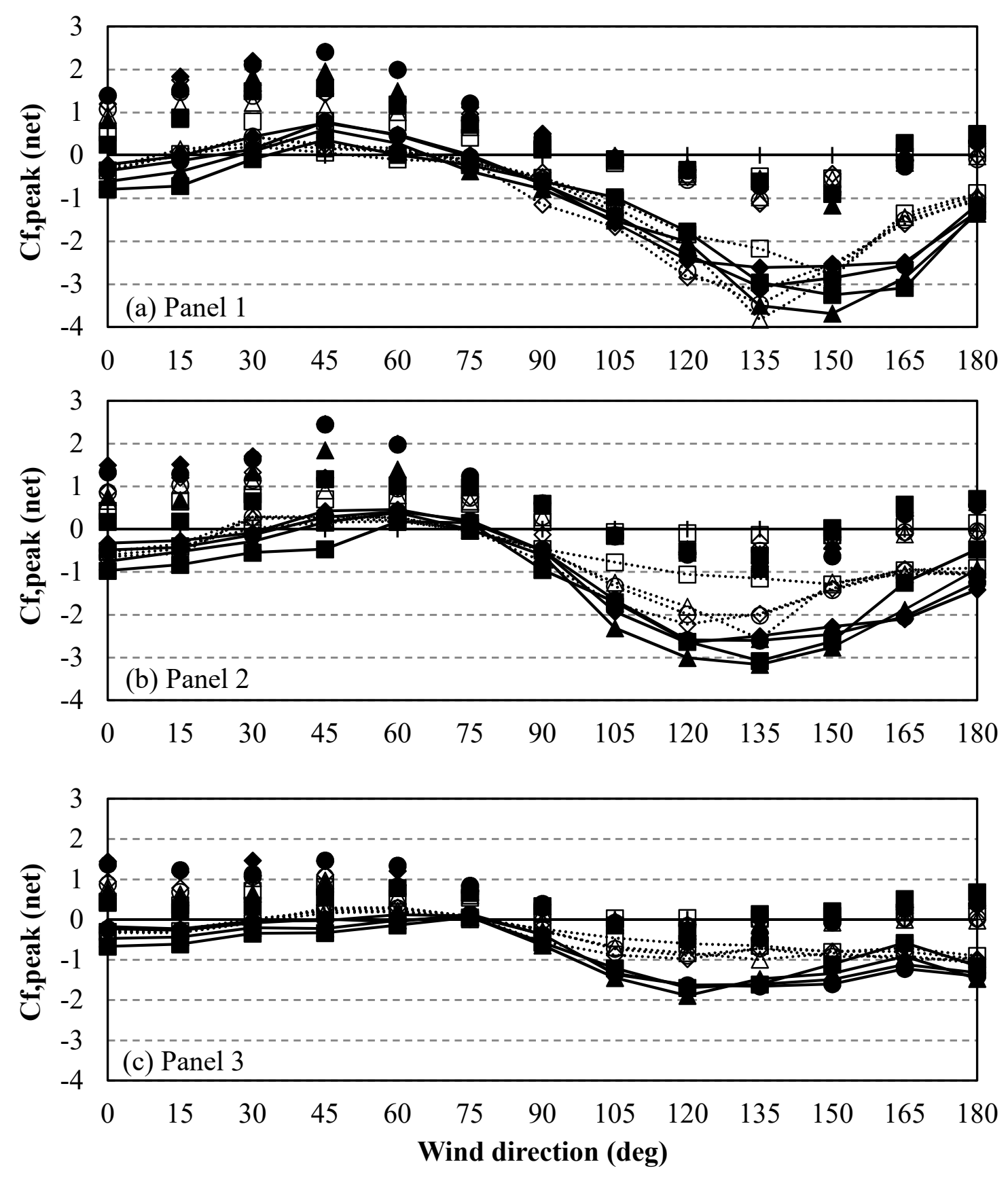

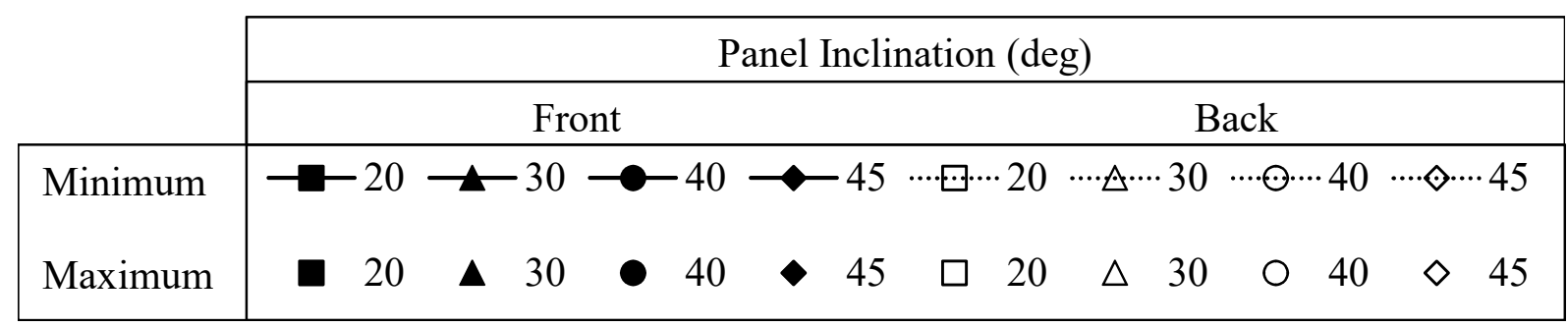

Figure 20. Net peak force coefficients for (a) panel 1, (b) panel 2 and (c) panel 3 when attached to $16 \mathrm{~m}$ high building, front and back location. 

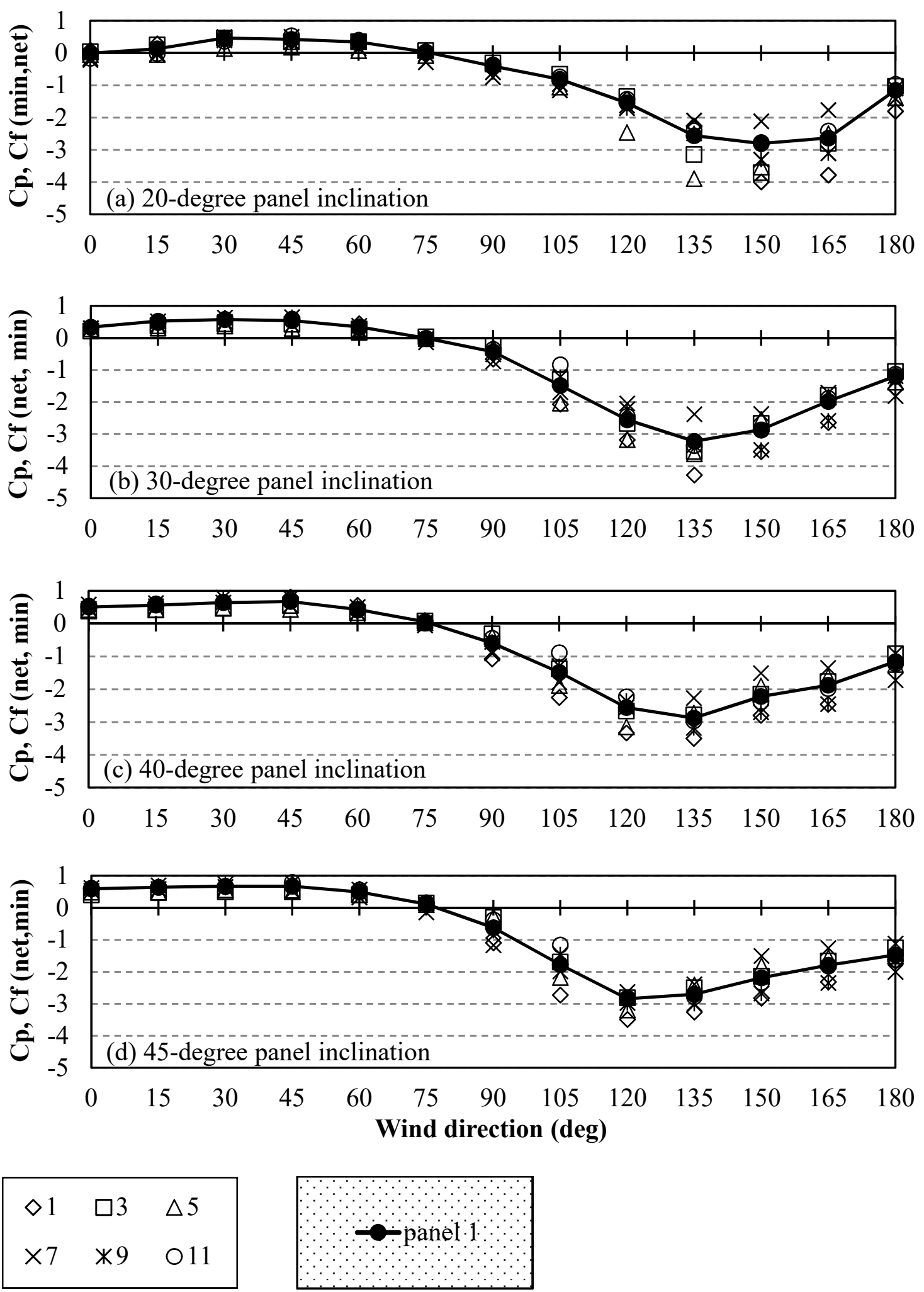

Figure 21. Comparison of local Cp and panel Cf for (a) 20-, (b) 30-, (c) 40- and (d) 45-degree panel inclination for $7 \mathrm{~m}$ high building and front location. 

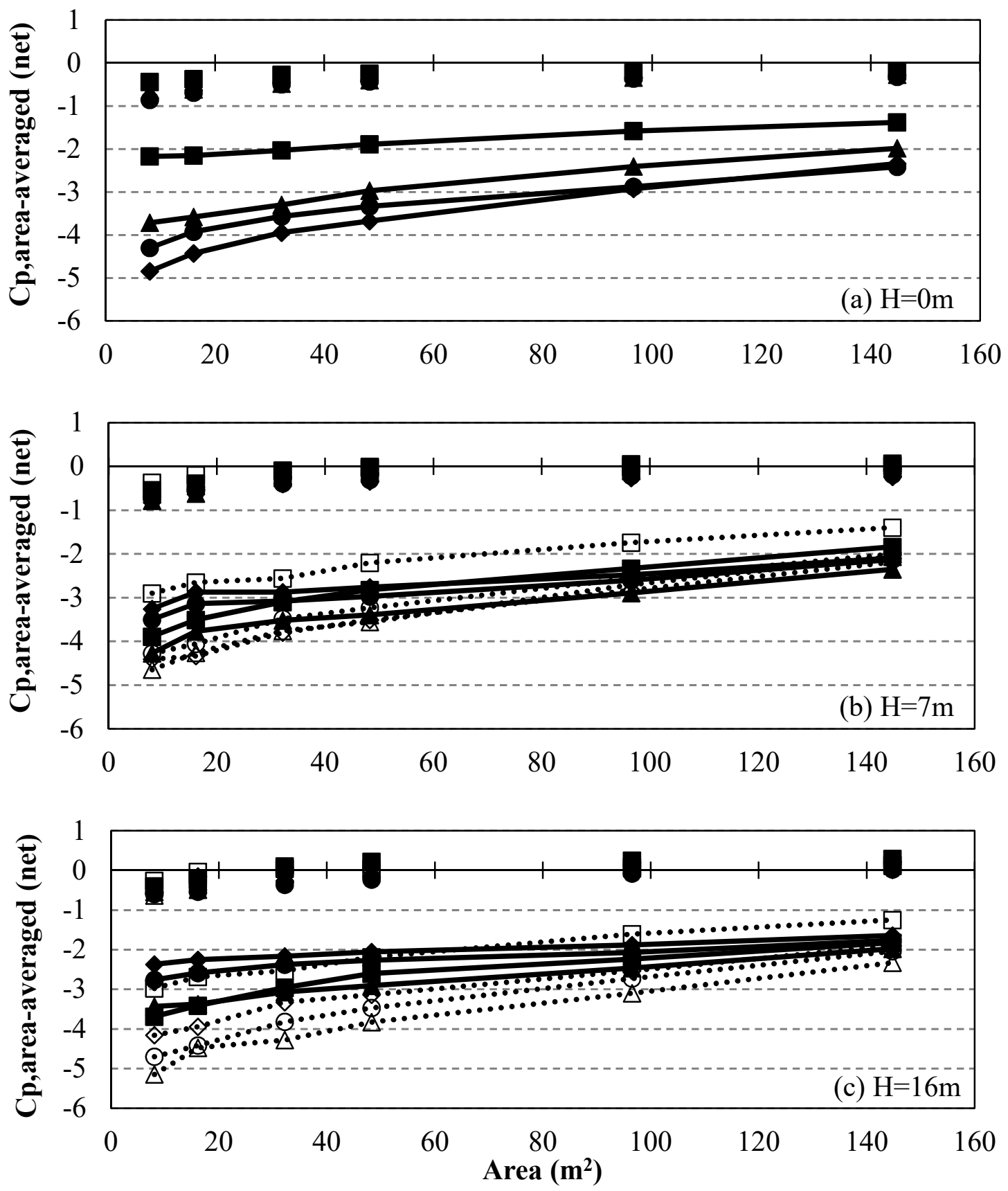

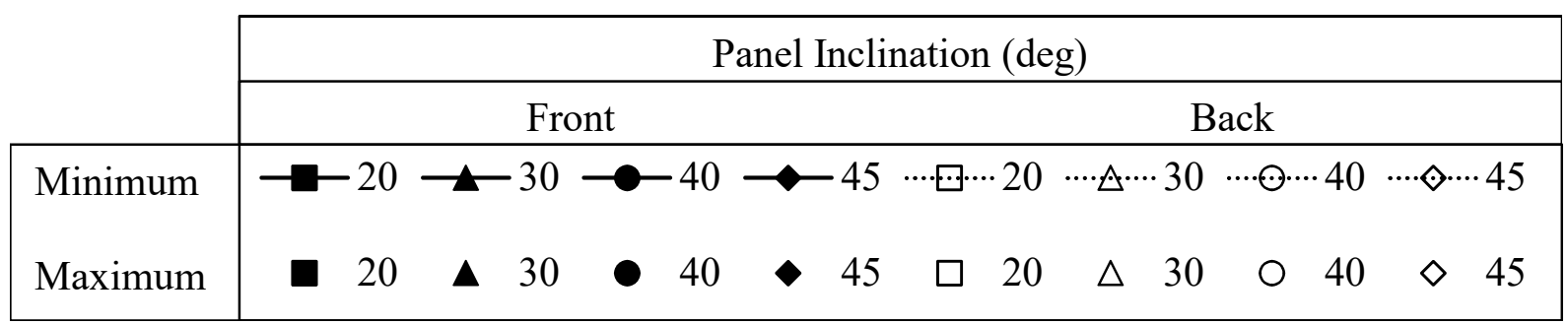

Figure 22. Net peak area-averaged pressure coefficients for panels (a) stand-alone, (b) attached to $7 \mathrm{~m}$ high building and (c) attached to $16 \mathrm{~m}$ building considering 135-degree wind direction. 


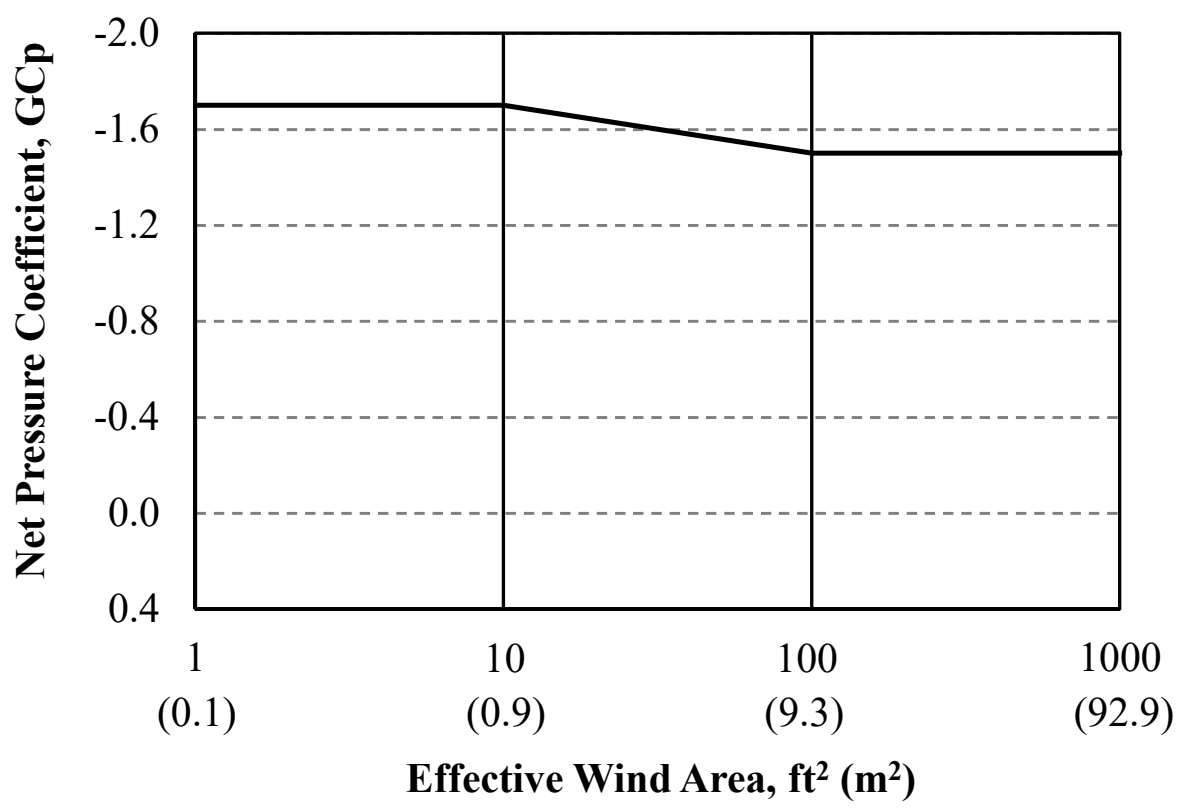

Figure 23. Simplified provisions (ASCE 7 format) for the design of solar panels on roofs or on ground. 


\section{List of Table Captions}

Table 1. Previous studies on solar panels attached on flat roofs.

Table 2. Previous studies on solar panels attached near roof corners and edges. 
Table 1. Previous studies on solar panels attached on flat roofs.

\begin{tabular}{llllll}
\hline & Country & Scale & $\begin{array}{l}\text { Building Model } \\
\text { Dimensions (m) }\end{array}$ & $\begin{array}{l}\text { PV Model } \\
\text { Dimensions (m) }\end{array}$ & $\begin{array}{l}\text { Inclination } \\
\text { Angle (deg.) }\end{array}$ \\
\hline Radu et al. (1986) & Romania & $1: 50$ & $0.3 \times 0.43 \times 0.3$ & $0.04 \times 0.02$ & 30 \\
Radu and Axinte (1989) & Romania & $1: 50$ & N/A & $0.08 \times 0.04$ & N/A \\
$\begin{array}{l}\text { Wood et al. (2001) } \\
\text { Ruscheweyh and }\end{array}$ & Australia & $1: 100$ & $0.41 \times 0.27 \times 0.12$ & $0.41 \times 0.027$ & 0 \\
$\begin{array}{l}\text { Windhovel (2011) } \\
\text { Saha et al. (2011) }\end{array}$ & Germany & $1: 50$ & N/A & N/A & 30 \\
\hline
\end{tabular}

Table 2. Previous studies on solar panels attached near roof corners and edges.

\begin{tabular}{|c|c|c|c|c|c|}
\hline & Country & Scale & $\begin{array}{l}\text { Building Model } \\
\text { Dimensions (m) }\end{array}$ & $\begin{array}{l}\text { PV Model } \\
\text { Dimensions (m) }\end{array}$ & $\begin{array}{l}\text { Inclination } \\
\text { Angle (deg.) }\end{array}$ \\
\hline Hosoya et al. (2001) & $\mathrm{CO}, \mathrm{USA}$ & $1: 50$ & $0.182 \times 0.274 \times 0.08$ & $0.0244 \times 0.0244 \times 0.0244$ & N/A \\
\hline Bronkhorst et al. (2010) & $\begin{array}{l}\text { Netherlands/ } \\
\text { Germany }\end{array}$ & $1: 50$ & $0.6 \times 0.8 \times 0.2$ & $0.024 \times 0.6$ & 35 \\
\hline Bienkiewicz et al. (2009) & $\mathrm{CO}, \mathrm{USA}$ & Variable & & & \\
\hline Erwin et al. (2011) & FL, USA & $\begin{array}{l}\text { Full- } \\
\text { Scale }\end{array}$ & $4.3 \times 4.3 \times 3.2$ & $1.57 \times 0.95 \times 0.041$ & $\begin{array}{l}-45,-15,0 \\
15,45\end{array}$ \\
\hline Saha et al. (2011) & Japan & $1: 50$ & $0.45 \times 0.45 \times 0.4$ & $0.02 \times 0.04$ & $0,15,30,45$ \\
\hline
\end{tabular}

